\title{
The bacterial effector HopZ1a acetylates MKK7 to suppress plant immunity
}

\author{
José S. Rufián $^{1,2 *}$ (D), Javier Rueda-Blanco ${ }^{1 *}$ (D) Diego López-Márquez ${ }^{1}$ (D), Alberto P. Macho² ${ }^{\text {(D) }}$, \\ Carmen R. Beuzón ${ }^{1}$ (D) and Javier Ruiz-Albert ${ }^{1}$ (D)
}

${ }^{1}$ Departamento Biología Celular, Genética y Fisiología, Instituto de Hortofruticultura Subtropical y Mediterránea, Universidad de Málaga-Consejo Superior de Investigaciones Científicas

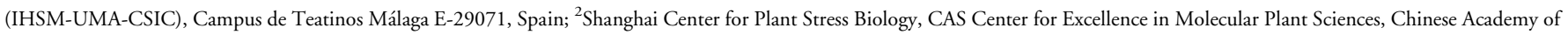
Sciences, Shanghai 201602, China

Author for correspondence: Javier Ruiz-Albert

Email: javieruizal@uma.es

Received: 25 November 2020

Accepted: 22 April 2021

New Phytologist (2021)

doi: $10.1111 /$ nph.17442

Key words: acetylation, Arabidopsis, HopZ1a, MAP kinases, MKK, plant immunity, Pseudomonas syringae, type III secretion system.

\section{Summary}

- The Pseudomonas syringae type III secretion system translocates effector proteins into the host cell cytosol to suppress plant basal immunity. Effector HopZ1a suppresses local and systemic immunity triggered by pathogen-associated molecular patterns (PAMPs) and effectors, through target acetylation. HopZ1a has been shown to target several plant proteins, but none fully substantiates HopZ1a-associated immune suppression. Here, we investigate Arabidopsis thaliana mitogen-activated protein kinase kinases (MKKs) as potential targets, focusing on AtMKK7, a positive regulator of local and systemic immunity.

- We analyse HopZ1a interference with AtMKK7 by translocation of HopZ1a from bacteria inoculated into Arabidopsis expressing MKK7 from an inducible promoter. Reciprocal phenotypes are analysed on plants expressing a construct quenching MKK7 native expression. We analyse HopZ1a-MKK7 interaction by three independent methods, and the relevance of acetylation by in vitro kinase and in planta functional assays.

- We demonstrate the AtMKK7 contribution to immune signalling showing MKK7dependent flg22-induced reactive oxygen species (ROS) burst, MAP kinas (MAPK) activation and callose deposition, plus AvrRpt2-triggered MKK7-dependent signalling. Furthermore, we demonstrate HopZ1a suppression of all MKK7-dependent responses, HopZ1a-MKK7 interaction in planta and HopZ1a acetylation of MKK7 with a lysine required for full kinase activity.

- We demonstrate that HopZ1a targets AtMKK7 to suppress local and systemic plant immunity.

\section{Introduction}

Pseudomonas syringae is a phytopathogenic bacterium that uses a type III secretion system (T3SS) to inject proteins, known as effectors, directly into the host cell cytosol. Several P. syringae type III effectors (T3Es) can suppress the plant defence response triggered upon recognition by plant pattern recognition receptors (PRRs) of conserved pathogen-associated molecular patterns (PAMPs) such as bacterial flagellin, known as PAMP-triggered immunity (PTI) (Boller \& Felix, 2009). In turn, T3Es can be detected by plant resistance proteins containing nucleotidebinding domains and leucine-rich repeats (NLRs), triggering a stronger line of defence known as effector-triggered immunity (ETI), which usually ensues a type of programmed cell death referred to as the hypersensitive response (HR), resulting in a drastic restriction of pathogen growth (Chiang \& Coaker, 2015). Furthermore, other T3Es can suppress ETI, therefore enabling pathogen growth (Jones \& Dangl, 2006). The local activation of

*The first two authors contributed equally to this work. immunity also triggers a plant defence response that goes beyond the local tissue, known as systemic acquired resistance (SAR) (reviewed by Spoel \& Dong, 2012; Klessig et al., 2018; Shine et al., 2019).

HopZ1a is a $P$. syringae T3E that suppresses plant immunity, including: (1) basal resistance or PTI triggered against $P$. syringae pv. tomato (Pto) DC3000 (Macho et al., 2010; Lewis et al., 2014); (2) ETI triggered against the heterologous effectors AvrRpt2, AvrRps4 and AvrRpm1 (Macho et al., 2010; Rufián et al., 2015); and (3) SAR triggered against either virulent or avirulent bacteria (Macho et al., 2010; Rufián et al., 2015). Conversely, HopZ1a triggers ETI in Arabidopsis upon recognition by the NLR ZAR1 (HOPZ-ACTIVATED RESISTANCE 1) (Lewis et al., 2010), a response independent of salicylic acid (SA) and EDS1 (Lewis et al., 2010; Macho et al., 2010).

HopZ1a belongs to the YopJ/HopZ superfamily of T3Es, which includes representatives from both animal and plant pathogens (reviewed by Ma \& Ma, 2016). Many of these T3Es function as acetyltransferases, among other biochemical activities 
(Trosky et al., 2004; Zhou et al., 2005; Mittal et al., 2006; Jones et al., 2008; Lee et al., 2015). HopZ1a displays acetyltransferase activity, with varying degrees of efficiency, on some of its interacting plant partners (Lee et al., 2012, 2019; Jiang et al., 2013; Lewis et al., 2013; Zhang et al., 2016; Bastedo et al., 2019). HopZ1a acetyltransferase activity is dependent on the integrity of the catalytic triad cysteine (C216), as a HopZ1a ${ }^{\mathrm{C} 216 \mathrm{~A}}$ mutant behaves as a catalytically inactive mutant (Lee et al., 2012). Therefore, C216 is essential for all described HopZ1a virulence and avirulence functions in planta (Ma et al., 2006; Lewis et al., 2008; Macho et al., 2010; Lewis et al., 2014; Rufián et al., 2015). Additionally, HopZ1a autoacetylates in two serine residues that are essential for HopZ1a function (Ma et al., 2015) and in a lysine residue that partially contributes to HopZ1a function (Lee et al., 2012; Ma et al., 2015; Rufián et al., 2015).

Some plant proteins have been described to interact with HopZ1a, and proposed as targets of its virulence activity, such as isoflavone biosynthesis enzyme HID1, JASMONATE ZIM DOMAIN (JAZ) transcriptional repressors, or tubulin (Zhou et al., 2011; Lee et al., 2012; Jiang et al., 2013). Additional plant proteins participate in the recognition of HopZ1a by the plant defence system (Albers et al., 2019; Bastedo et al., 2019; Liu et al., 2019). HopZ1a-dependent acetylation of the receptor-like cytoplasmic kinase (RLCK) ZED1 (HOPZ-ETIDEFICIENT 1), a pseudokinase that acts as a decoy, is detected by the ZAR-1 resistance protein, triggering ETI (Lewis et al., 2010, 2013). Resistance requires the formation of a HopZ1aZED1-ZAR1 complex, with ZED1 acting as an adaptor, but also involves additional RLCKs such as PBS1-like (PBL) kinases (Bastedo et al., 2019), SZE1 and SZE2 (SUPPRESSOR OF ZED) kinases (Liu et al., 2019), or the scaffold protein remorin (Albers et al., 2019).

Targeting of host kinases is a common theme among T3Es within the YopJ/HopZ superfamily. The Yersinia T3E YopJ acetylates key serine and threonine residues of several host mitogen-activated protein kinase kinases (MAP2Ks or MKKs) and MAP kinase kinase kinases (MAP3Ks), blocking its phosphorylation, which in turn leads to inactivation of downstream immune signalling (Mittal et al., 2006; Mukherjee et al., 2006; Meinzer et al., 2012; Paquette et al., 2012; Ma \& Ma, 2016). YopJ can also acetylate lysine residues of several of its target kinases (Mukherjee et al., 2006; Paquette et al., 2012). Similarly, AvrA from Salmonella and VopA from Vibrio acetylate key serine, threonine and lysine residues of their corresponding target MKKs, resulting in inhibition of kinase activity and suppression of immune responses (Trosky et al., 2007; Jones et al., 2008).

In plants, MAP kinase (MAPK)-dependent signalling networks participate in defence against pathogens, as PRR recognition of PAMPs leads to activation of MAPK modules and ultimately to the immune response (reviewed by Pitzschke et al., 2009; Feng et al., 2012; Meng \& Zhang, 2013). HopZ1a suppresses MAPK activation in Arabidopsis (Lewis et al., 2014), while HopZ3 directly interacts with MAPK4 (Lee et al., 2015). Furthermore, other P. syringae T3Es can suppress defence signalling by targeting MAPK cascades, such as HopAI1 that interferes with several MAPKs (J. Zhang et al., 2007; Zhang et al.,
2012), or HopF2 that blocks MKK5 phosphorylation (Wang et al., 2010).

Although several reports have described plant targets for HopZ1a (Zhou et al., 2011; Lee et al., 2012; Jiang et al., 2013; Albers et al., 2019), the molecular mechanisms of HopZ1amediated suppression of immunity, particularly those regarding ETI or SAR, remain unclear. Given the broad plant defence suppression abilities of HopZ1a, the proclivity of YopJ/HopZfamily T3Es to target host kinases, the targeting of decoy pseudokinase ZED1 by HopZ1a, and the importance of MAPK cascades as regulators of immune signalling, we considered MKKs as potential virulence targets of HopZ1a involved in its suppression of PTI, ETI and SAR. The Arabidopsis genome presents 10 genes encoding MKKs, of which only eight are likely to be expressed (Zhang et al., 2008). Among these, MKK7, MKK3 and the functionally redundant pairs MKK1/2 and MKK4/5 have been identified as positive regulators of plant defence (Asai et al., 2002; Doczi et al., 2007; X. Zhang et al., 2007; Meng \& Zhang, 2013), but only MKK7 has been shown to be essential for SAR activation (X. Zhang et al., 2007). Considering the evidence available, we decided to investigate MKK7 as a potential target for HopZ1a.

In this work, we show that MKK7 contributes to PAMPtriggered callose deposition, reactive oxygen species (ROS) burst and MAPK activation, contributing to resistance against Pto DC3000 and a nonpathogenic T3SS null mutant. We also demonstrate that MKK7 contributes to immune responses triggered by AvrRpt2. Markedly, we found that HopZ1a interacts with MKK7, and show that bacteria-delivered HopZ1a interferes with and suppresses MKK7-dependent PTI, ETI and SAR. Finally, we show that HopZ1a acetylates MKK7 in a conserved lysine residue, which we demonstrate to be essential for MKK7 activity, leading to a reduction of MKK7 self-phosphorylation.

\section{Materials and Methods}

\section{Bacterial strains and growth conditions}

Bacterial strains are shown in Table 1 along with the antibiotic concentration used for selection. Bacteria were grown at $37^{\circ} \mathrm{C}$ (Escherichia coli) or $28^{\circ} \mathrm{C}$ (Pseudomonas and Agrobacterium) in Luria-Bertani (LB) medium, supplemented with antibiotics when appropriate. Media used to grow plant-extracted bacteria contained $2 \mu \mathrm{g} \mathrm{ml}^{-1}$ cycloheximide to prevent fungal contamination.

\section{Plasmid generation}

Plasmids used in this work are listed in Table 2, primers are listed in Table 3. All PCRs were performed using Q5 High-Fidelity DNA Polymerase (New England Biolabs, Ipswich, MA, USA).

For $6 \times$ His-HopZ1a fusion proteins, HopZ1a and HopZ1a ${ }^{\mathrm{C} 216 \mathrm{~A}}$ open reading frames (ORFs) were PCR amplified using plasmids pAME30 and pAME27 as templates with primers $\mathrm{Z} 1 \mathrm{pET}-\mathrm{F} / \mathrm{R}$, and cloned into the $\mathrm{Nde \textrm {I }}$ and $\mathrm{BamHI}$ sites of vector pET28a $(+)$, generating pET28-Z1a and pET28-C2. 
Table 1 Bacterial strains used in this work.

\begin{tabular}{|c|c|c|}
\hline Strain & Reference & Antibiotic selection* \\
\hline Escherichia coli DH5 $\alpha$ & Hanahan (1983) & $\begin{array}{l}50 \mu \mathrm{g} \mathrm{ml}^{-1} \text { kanamycin (pENTR, pMD1, pTA7001, pGWB-luc) } \\
50 \mu \mathrm{gl}^{-1} \text { spectinomycin (pGWB505, pGWB554) }\end{array}$ \\
\hline Escherichia coli NCM631 & Govantes et al. (1996) & $\begin{array}{l}50 \mu \mathrm{g} \mathrm{ml}^{-1} \text { kanamycin (pET) } \\
100 \mu \mathrm{g} \mathrm{ml}^{-1} \text { ampicillin (pGEX) }\end{array}$ \\
\hline Pseudomonas syringae pv. tomato DC3000 & Cuppels (1986) & $15 \mu \mathrm{g} \mathrm{ml}^{-1}$ kanamycin (pAME) \\
\hline Pseudomonas fluorescens 55 & Huang et al. (1988); Jamir et al. (2004) & $\begin{array}{l}5 \mu \mathrm{g} \mathrm{ml}^{-1} \text { tetracycline (genomic) } \\
15 \mu \mathrm{g} \mathrm{ml}^{-1} \text { kanamycin (pAME) }\end{array}$ \\
\hline Agrobacterium tumefaciens C58C1 & Deblaere et al. (1985) & $\begin{array}{l}50 \mu \mathrm{g} \mathrm{ml}^{-1} \text { rifampicin (genomic) } \\
5 \mu \mathrm{gl}^{-1} \text { tetracycline (helper plasmid PGV2260) } \\
50 \mu \mathrm{g} \mathrm{ml}^{-1} \text { kanamycin (pMD1, pTA7001, pGWB-luc) } \\
50 \mu \mathrm{gl}^{-1} \text { spectinomycin (pGWB505, pGWB554) }\end{array}$ \\
\hline
\end{tabular}

*Genomic resistance or when carrying the indicated plasmids.

For GST-MKK7 fusion proteins, the MKK7 ORF was PCR amplified from Arabidopsis genomic DNA using primers MKK7-F/R1 and cloned into the BamHI-EcoRI sites of pGEX$5 \mathrm{X}-1$. Point mutants were then generated with the NZY Mutagenesis kit (NZY Tech, Portugal) using primers $M K K 7^{\mathrm{K} 74 \mathrm{R}} \mathrm{F} / \mathrm{R}$ and MKK $7^{\mathrm{K} 167 \mathrm{R}} \mathrm{F} / \mathrm{R}$. Mutations were verified by sequencing.

For Gateway-cloning intermediates, HopZ1a and HopZ1aC216A ORFs were PCR amplified using plasmids pAME30 and pAME27 as templates, and primers Z1a pENTRF/R. MKK7 ORF was PCR amplified from Arabidopsis genomic DNA using primers MKK7 pENTR-F/R. All fragments were cloned independently into the $A s c \mathrm{I}$ and Not $\mathrm{sites}$ of pENTR/D (Invitrogen, Waltham, MA, USA). After validation by sequencing, we used Gateway LR Clonase II Enzyme mix (Invitrogen) to subclone the fragments into their destination vectors (Table 1).

\section{Dexamethasone treatment}

Dexamethasone (DEX) (Sigma, USA) stock was prepared at $10 \mathrm{mM}$ in ethanol. To induce MKK7 expression from the dexamethasone-inducible promoter, we infiltrated leaves with either a $10 \mu \mathrm{M}$ DEX solution in water or $0.1 \%$ ethanol in water (mock). Plant discs and seedlings were incubated either with $3 \mathrm{ml}$ DEX or mock solution for $24 \mathrm{~h}$.

\section{Plant material and bacterial inoculations}

Arabidopsis thaliana (Col-0) and derivatives MKK7-DEX, asMKK7 (X. Zhang et al., 2007) and MKK7-DEX/zarl-1 were grown in soil, in temperature-controlled chambers, at $21^{\circ} \mathrm{C}$ with a controlled photoperiod of $8 \mathrm{~h}: 16 \mathrm{~h}$, light: dark and a light intensity of $200 \mu \mathrm{mol} \mathrm{m}{ }^{-2} \mathrm{~s}^{-1}$. Nicotiana benthamiana plants were grown in similar conditions except for a $16 \mathrm{~h}: 18 \mathrm{~h}$, light : dark photoperiod. Arabidopsis transgenic plants expressing $M K K 7-3 X F L A G$ or $M K K 7^{K 167 R}-3 X F L A G$ were generated through the floral dipping method (Clough \& Bent, 1998).

For P. syringae growth assays, bacterial lawns were grown on LB plates for $48 \mathrm{~h}$ at $28^{\circ} \mathrm{C}$, scrapped off the plates and resuspended into $2 \mathrm{ml}$ of $10 \mathrm{mM} \mathrm{MgCl}_{2}$. The $\mathrm{OD}_{600}$ was adjusted to $0.1\left(5 \times 10^{7} \mathrm{CFU} \mathrm{ml}^{-1}\right)$ and serial dilutions were made to reach the final inoculum dose $\left(5 \times 10^{4} \mathrm{CFU} \mathrm{m}{ }^{-1}\right)$. MKK7-DEX plants were infiltrated with either DEX or mock solution $2 \mathrm{~h}$ before bacterial inoculation. Three fully expanded leaves of 5-wkold Arabidopsis plants were inoculated using a 1-ml syringe without a needle. Samples were taken from infiltrated leaves at $4 \mathrm{~d}$ post inoculation (dpi) using a 10-mm-diameter cork-borer (Sigma, USA). One disc was taken per leaf, three discs per plant, placed into $1 \mathrm{ml}$ of $10 \mathrm{mM} \mathrm{MgCl}_{2}$, and homogenised by mechanical disruption. Serial dilutions of the resulting bacterial suspensions were plated onto LB plates supplemented with $2 \mu \mathrm{g} \mathrm{ml}^{-1}$ of cycloheximide.

Competitive index assays were performed on fully expanded leaves of 4- to 5-wk-old plants as previously described for Arabidopsis (Macho et al., 2016).

SAR assays were performed as described by Rufián et al. (2019) with modifications. Briefly, three fully expanded leaves of 5 -wk-old plants were infiltrated either with DEX or mock solution. At $2 \mathrm{~h}$ after treatment, the same leaves were infiltrated either with $10 \mathrm{mM} \mathrm{MgCl}_{2}$ (mock), or a $5 \times 10^{5} \mathrm{CFU} \mathrm{m}^{-1}$ bacterial suspension of either $P$. fluorescens $\mathrm{pLN} 18$ or $P$. fluorescens expressing HopZ1a. At 3 dpi, three distal leaves were inoculated with a $5 \times 10^{4} \mathrm{CFU} \mathrm{ml}^{-1}$ suspension of DC3000 prepared as described above. At $4 \mathrm{~d}$ after DC3000 inoculation, tissue was collected as described above. Numbers of replicates and experiments, error and statistical test for growth assays are detailed in the corresponding figure legends.

Transient expression assays in $N$. benthamiana were performed as previously described (Rufián et al., 2015) by infiltration of 5wk-old plants with Agrobacterium C58C1 carrying the corresponding binary plasmids (Table 1 ). When required, plants were treated with DEX $24 \mathrm{~h}$ after agroinfiltration. Samples were analysed at $48 \mathrm{~h}$ post inoculation (hpi).

\section{Measurement of ROS generation}

Oxidative burst was quantified as previously described (Sang $\&$ Macho, 2017). Plant discs were incubated overnight with either DEX or mock solution. ROS was elicited with $100 \mathrm{nM} \mathrm{flg} 22$ (GeneScript, Piscataway, NJ, USA). In total, 20 leaf discs from 4-wk-old plants were used for each condition. Luminescence was measured using a GloMax 96 Microplate Luminometer (Promega, Madison, WI, USA). 
Table 2 Plasmids used in this work.

\begin{tabular}{|c|c|c|c|c|}
\hline Name & Promoter & Expressed protein & Resistance & Reference \\
\hline pAME30 & $n p t / l$ & HopZ1a & Amp, $\mathrm{Km}$ & Macho et al. (2010) \\
\hline pAME27 & nptII & HopZ1a ${ }^{C 216 A}$ & $\mathrm{Amp}, \mathrm{Km}$ & Macho et al. (2010) \\
\hline pAME8 & nptII & AvrRpt2 & Amp, $\mathrm{Km}$ & Macho et al. (2009) \\
\hline $\mathrm{pENTR}^{T M} / \mathrm{D}-\mathrm{TOPO}$ & - & - & $\mathrm{Km}$ & Invitrogen \\
\hline pENTR-Z1a & - & HopZ1a & $\mathrm{Km}$ & This work \\
\hline pENTR-C2 & - & HopZ1a ${ }^{C 216 A}$ & $\mathrm{Km}$ & This work \\
\hline pENTR-MKK7 & - & MKK7 & $\mathrm{Km}$ & This work \\
\hline pENTR-MKK $7^{\text {K74R }}$ & - & MKK7 & $\mathrm{Km}$ & This work \\
\hline pENTR-MKK $7^{\mathrm{K} 167 R}$ & - & MKK7 $167 \mathrm{R}$ & $\mathrm{Km}$ & This work \\
\hline pENTR HopAF1 & - & HopAF1 & $\mathrm{Km}$ & This work \\
\hline pENTR-MKK4 & - & MKK4 & $\mathrm{Km}$ & This work \\
\hline pENTR-MKK5 & - & MKK5 & $\mathrm{Km}$ & This work \\
\hline pGT-Turquoise2 & - & mTurquoise2 & Amp & Rufián et al. (2018a) \\
\hline pENTR-Turquoise2 & - & mTurquoise2 & $\mathrm{Km}$ & This work \\
\hline pENTR-CBL-RFP & - & CBL-RFP & $\mathrm{Km}$ & This work \\
\hline PMD1-HA & $35 S$ & - & $\mathrm{Km}$ & Li et al. (2013) \\
\hline pMD-MKK7 & $35 S$ & MKK7 -HA & $\mathrm{Km}$ & This work \\
\hline pMD-MKK $7^{\text {K74R }}$ & $35 S$ & MKK $7^{\mathrm{K} 74 \mathrm{R}}-\mathrm{HA}$ & $\mathrm{Km}$ & This work \\
\hline pMD-MKK $7^{\mathrm{K} 167 \mathrm{R}}$ & $35 S$ & MKK $7^{\mathrm{K} 167 \mathrm{R}}-\mathrm{HA}$ & $\mathrm{Km}$ & This work \\
\hline pMD-GFP & $35 S$ & GFP-HA & $\mathrm{Km}$ & Rufián et al. (2018b) \\
\hline pMD-mTurq & $35 S$ & mTurquoise2-HA & $\mathrm{Km}$ & This work \\
\hline pTA7001-3xFLAG & $35 S-G V G$ & - & $\mathrm{Km}$ & Li et al. (2013) \\
\hline pTA7001-Z1 & $35 S-G V G$ & HopZ1a-3xFLAG & $\mathrm{Km}$ & This work \\
\hline pTA7001-C2 & $35 S-G V G$ & HopZ1a ${ }^{C 216 A}-3 \times F L A G$ & $\mathrm{Km}$ & This work \\
\hline pGWB-nLUC & 355 & nLuc & $\mathrm{Km}$ & Wang et al. (2019) \\
\hline pGWB-CLUC & $35 S$ & cLuc & $\mathrm{Km}$ & Yu et al. (2020) \\
\hline pGWB-C2-nluc & $35 S$ & HopZ1a $a^{C 216 A}$-nluc & $\mathrm{Km}$ & This work \\
\hline pGWB-AF1-nluc & $35 S$ & HopAF1-nluc & $\mathrm{Km}$ & This work \\
\hline pGWB-K74R-cluc & $35 S$ & cluc-MKK $7^{K 74 R}$ & $\mathrm{Km}$ & This work \\
\hline pGWB505 & $35 S$ & GFP & Sp & Nakagawa et al. (2007) \\
\hline pGWB554 & $35 S$ & RFP & $\mathrm{Sp}$ & Nakagawa et al. (2007) \\
\hline pGWB505-HopZ1a & $35 S$ & HopZ1a-GFP & Sp & This work \\
\hline pGWB505-C2 & $35 S$ & HopZ1a ${ }^{\mathrm{C} 216 \mathrm{~A}}-$ GFP & Sp & This work \\
\hline pGWB554-MKK7 & $35 S$ & MKK7-RFP & Sp & This work \\
\hline pGWB554-K74R & $35 S$ & $M K K 7^{K 74 R}-R F P$ & Sp & This work \\
\hline pGWB554-MKK4 & $35 S$ & MKK4-RFP & Sp & This work \\
\hline pGWB554-MKK5 & $35 S$ & MKK5-RFP & $\mathrm{Sp}$ & This work \\
\hline pGWB502-CBL & $35 S$ & CBL-RFP & Sp & This work \\
\hline pTA7001-MKK7 & $35 S-G V G$ & MKK7-3xFLAG & $\mathrm{Km}$ & This work \\
\hline pTA7001-K74R & $35 S-G V G$ & MKK $7^{\mathrm{K} 74 \mathrm{R}}-3 \times \mathrm{FLAG}$ & $\mathrm{Km}$ & This work \\
\hline pTA7001-K167R & $35 S-G V G$ & MKK $7^{\mathrm{K} 167 \mathrm{R}}-3 \times \mathrm{FLAG}$ & $\mathrm{Km}$ & This work \\
\hline pET28-Z1a & T7 & $6 \times$ His-HopZ1a & $\mathrm{Km}$ & Rufián et al. (2015) \\
\hline pET28-C2 & T7 & $6 \times \mathrm{His}^{-H o p Z 1 a^{\mathrm{C} 216 \mathrm{~A}}}$ & $\mathrm{Km}$ & Rufián et al. (2015) \\
\hline $\mathrm{pET} 28-\mathrm{K} 2$ & T7 & HopZ1 $a^{\mathrm{K} 289 R}$ & $\mathrm{Km}$ & Rufián et al. (2015) \\
\hline PGEX-5X-1 & tac & GST & Amp & GE Healthcare \\
\hline pGEX-MKK7 & tac & GST-MKK7 & Amp & This work \\
\hline pGEX-MKK $7^{K 74 R}$ & $\operatorname{tac}$ & GST-MKK $7^{K 74 R}$ & Amp & This work \\
\hline pGEX-MKK $7^{\mathrm{K} 167 \mathrm{R}}$ & tac & GST-MKK $7^{K 167 R}$ & Amp & This work \\
\hline
\end{tabular}

\section{Callose deposition}

Callose deposition was detected by aniline blue staining (Adam \& Somerville, 1996). Leaves of 4-wk-old plants were infiltrated either with DEX or mock solution. At $24 \mathrm{~h}$ after treatment, the same leaves were infiltrated with $100 \mathrm{nM} \mathrm{flg} 22$ (for flg22induced callose deposition experiments) or with the indicated bacterial strain at $5 \times 10^{7} \mathrm{CFU} \mathrm{ml}^{-1}$ (for HopZ1a-interference assays). Samples were collected $18 \mathrm{~h}$ after the second inoculation for aniline staining. Three plants were used for treatment, using two leaves per plant, and taking two representative images per leaf. Callose deposition was measured using FIJ distribution of IMAGEJ software.

\section{Plant protein extraction}

For MAP kinase activation assays, 10-d-old seedlings incubated in liquid Murashige \& Skoog (MS) medium were treated with either DEX or mock solution. At $24 \mathrm{~h}$ later, treatment solutions were removed, and seedlings were immersed into a $100 \mathrm{nM} \mathrm{flg} 22$ solution. Ten seedlings were collected per sample and treatment, and processed as previously described (Yu et al., 2020). 
Table 3 Primers used in this work.

\begin{tabular}{|c|c|c|}
\hline Name & Sequence & Restriction site \\
\hline pENTR-Z1-F & AAGCGGCCGCCATGGGAAATGTATGCGTCG & Notl \\
\hline pENTR-Z1-R & AAGGCGCGCCCGCGCTGCTCTTCGGCAAG & Ascl \\
\hline pENTR-MKK7-F & AAGCGGCCGCCATGGCTCTTGTTCGTAAACGC & Notl \\
\hline pENTR-MKK7-R & AAGGCGCGCCCAAGACTTTCACGGAGAAAAGG & Ascl \\
\hline pENTR-MKK4-F & AAGCGGCCGCCATGAGACCGATTCAATCGCCT & Notl \\
\hline pENTR-MKK4-R & AAGGCGCGCCCTGTGGTTGGAGAAGAAGACGA & Ascl \\
\hline pENTR-MKK5-F & AAGCGGCCGCCATGAAACCGATTCAATCTCCTTCTGG & Notl \\
\hline pENTR-MKK5-R & AAGGCGCGCCCAGAGGCAGAAGGAAGAGGACG & Ascl \\
\hline MKK7-K167R-F & AGAGACATCAGACCTGCGAATC & - \\
\hline MKK7-K167R-R & TTCGCAGGTCTGATGTCTCTG & - \\
\hline$M K K 7^{K 74 R}-F$ & AGATATACGCTCTGAGATCAGTCAACGGCGACATGAGTCC & - \\
\hline$M K K 7^{\mathrm{K} 74 \mathrm{R}_{-} \mathrm{R}}$ & GGACTCATGTCGCCGTTGACTGATCTCAGAGCGTATATCT & - \\
\hline pENTR-HopAF1 F & CCGCGGCCGCCATGGGACTATGTATTTCAAAAC & Notl \\
\hline pENTR-HopAF1 R & TCGGCGCGCCCTAAAGCGACCAAATGCTTTATG & Ascl \\
\hline pENTR-Turq2 F & AAGCGGCCGCCATGGTGAGCAAGGGCGAGGAGC & Notl \\
\hline pENTR-Turq2 R & AAGGCGCGCCCTTACTTGTACAGCTCGTCCATGC & Ascl \\
\hline \multirow[t]{2}{*}{ CBL-RFP Fw } & CACCATGGGCTGCTTCCACTCAAAGGCAGC & - \\
\hline & AAAAGAATTTATGGCCTCCTCCGAGGACGTC & \\
\hline RFP Rv & TTAGGCGCCGGTGGAGTGGC & - \\
\hline pGEX-MKK7-F & AAGGATCCCCGCTCTTGTTCGTAAACGCC & $\mathrm{BamHI}$ \\
\hline PGEX-MKK7-R2 & AAGAATTCCTAAAGACTTTCACGGAGAAAAGG & EcoRI \\
\hline qPCR-MKK7-F & GTAAAGAATCGAGTGAGAG & - \\
\hline qPCR-MKK7-R & AATTGCGATTTGGGTCACCC & - \\
\hline qPCR-MKK9-F & TCCGGGAAGATCTTTGATTC & - \\
\hline qPCR-MKK9-R & CGATTTTCСССТAАСАTTCTG & - \\
\hline$q \mathrm{PCR}-\mathrm{MKK} 4-\mathrm{F}$ & GAGGTTTCCTTTCCCTGTGA & - \\
\hline$q \mathrm{PCR}-\mathrm{MKK} 4-\mathrm{R}$ & СТСТСТGCAAGCAACACGAG & - \\
\hline qPCR-MKK5-F & CGTCGTCATATCGTTCATCG & - \\
\hline qPCR-MKK5-R & CATTGTTTGTGCCAAGATCC & - \\
\hline$q$ PCR-ALD1-F & TCССTGATCTGGCTATGACC & - \\
\hline$q$ PCR-ALD1-R & GAAACTTCAATCGCGACCTC & - \\
\hline AtAct-F & CTAAGCTCTCAAGATCAAAGGCTTA & - \\
\hline AtAct-R & ACTAAAACGCAAAACGAAAGCGGTT & - \\
\hline$m k k 7-\mathrm{F}$ & CGATTCTGATAGGTAACACAAAGC & - \\
\hline$m k k 7-R$ & CCACCGTCCATATACTCCATG & - \\
\hline Spm-F & TACGAATAAGAGCGTCCATTTTAGAGTGA & - \\
\hline
\end{tabular}

For PR1 accumulation assays in local tissue, two fully expanded Arabidopsis young leaves were treated either with DEX or mock solution. At $2 \mathrm{~h}$ later, the same leaves were inoculated with either $10 \mathrm{mM} \mathrm{MgCl}_{2}$ (mock) or a $5 \times 10^{5} \mathrm{CFU} \mathrm{ml}^{-1}$ bacterial solution. Samples were taken at $2 \mathrm{dpi}$ and proteins extracted as described above. For PR1 detection in systemic tissue, three fully expanded leaves of 5-wk-old plants were infiltrated with either DEX or mock solution. At $2 \mathrm{~h}$ after treatment, the same leaves were infiltrated with either $10 \mathrm{mM} \mathrm{MgCl}_{2}$ solution (mock), or a $5 \times 10^{5} \mathrm{CFU} \mathrm{ml}^{-1}$ bacterial suspension of either P. fluorescens pLN18, or P. fluorescens expressing HopZ1a. Samples were taken from systemic leaves at $3 \mathrm{dpi}$, and proteins were extracted as described.

For immunoprecipitation assays, leaves were infiltrated with $10 \mu \mathrm{M}$ DEX solution $24 \mathrm{~h}$ after Agrobacterium inoculation, and samples were taken $6 \mathrm{~h}$ after DEX treatment using a $7.5-\mathrm{mm}$ diameter cork-borer (Sigma, USA). Forty leaf discs were taken per sample and homogenised into liquid nitrogen. Proteins were extracted and processed as previously described (Yadeta et al. 2017).

\section{Western blot hybridisations}

Samples were resolved on 10\% acrylamide SDS-PAGE gels and transferred to polyvinylidene difluoride (PVDF) Immobilon-P membranes (Millipore, Burlington, MA, USA). Western blots were performed using standard methods and the antibodies listed in Table 4. Membranes were developed using the Bio-Rad Clarity Western ECL Substrate (Bio-Rad, Hercules, CA, USA). Quantification of the intensity of the bands was determined using the FIJI distribution of IMAGEJ software.

\section{Luciferase assays}

Split-LUC assays were performed as previously described (Yu et al., 2020). A. tumefaciens strains containing the indicated plasmids (Table 2) were infiltrated into $N$. benthamiana leaves. At 2 dpi, leaves were infiltrated with $0.5 \mathrm{mM}$ luciferin in water, and kept in the dark for $5 \mathrm{~min}$ before charge coupled device (CCD) imaging. Images were taken with a VersArray 1300B (Roper 
Table 4 Antibodies used in this work.

\begin{tabular}{lll}
\hline Antibody & Working dilution & Reference \\
\hline Anti-His & $1: 5000$ & Sigma SAB1305538 \\
Anti-GST & $1: 10000$ & Sigma G7781 \\
Anti-HA & $1: 5000$ & Sigma H3663 \\
Anti-FLAG & $1: 5000$ & Sigma F1804 \\
Anti-luciferase & $1: 5000$ & Sigma L0159 \\
Anti-tubulin & $1: 1000$ & Abiocode M0267 \\
Anti-MPKs & $1: 5000$ & Cell Signaling Biotech \#4370 \\
Anti-PR1 & $1: 5000$ & Wang et al. (2005) \\
Anti-AcK & $1: 2500$ & Cell Signaling Biotech \#9441 \\
Anti-rabbit & $1: 10000$ & Sigma A6154 \\
Anti-mouse & $1: 80000$ & Sigma A9044 \\
\hline
\end{tabular}

Scientific, Tucson, AZ, USA). Protein accumulation was determined by immunoblot.

\section{Förster resonance energy transfer-fluorescence lifetime imaging (FRET-FLIM)}

FRET-FLIM experiments were performed as previously described (Rosas-Diaz et al., 2018). Nicotiana benthamiana plants transiently co-expressing donor (HopZ1a or HopZ1a ${ }^{\mathrm{C} 216 \mathrm{~A}}$ fused to GFP) and acceptor (AtMKK7 ${ }^{\mathrm{K} 74 \mathrm{R}}$ fused to RFP) proteins were visualised $24 \mathrm{~h}$ after infiltration using a Leica TCS SMD FLCS confocal microscope. Mean lifetimes are presented as mean \pm SEM based on eight images from three independent experiments.

\section{Conductivity assays}

Assays were performed as described by Rufián et al. (2018b) using samples from $P$. syringae-inoculated Arabidopsis Col-0 and asMKK7 leaves, or Agrobacterium-inoculated N. benthamiana leaves. Samples were taken at $2 \mathrm{hpi}$.

\section{Protein expression and purification in vitro}

Proteins were expressed in E. coli NCM631 after induction with $0.1 \mathrm{mM}$ IPTG at $20^{\circ} \mathrm{C}$. His-tagged proteins were purified using Ni-NTA agarose (Qiagen, USA), and GST-tagged proteins using Glutathione Sepharose 4B (GE Healthcare, Chicago, IL, USA) following standard methods. Protein concentration was determined using Bio-Rad protein assay (Bio-Rad).

\section{In vitro acetylation assay}

Assays were performed as described by Jiang et al. (2013), using $3 \mu \mathrm{g}$ of effector $\left(6 \times\right.$ His-HopZ1a, $6 \times$ His-HopZ1a ${ }^{\mathrm{C} 216 \mathrm{~A}}$ or $6 \times$ His-HopZ1 ${ }^{\mathrm{K} 289 \mathrm{R}}$ ) and $5 \mu \mathrm{g}$ of substrate (GST-MKK7 or GST-MKK $7^{\mathrm{K} 167 \mathrm{R}}$ ). Reactions were performed in the presence of the cofactor inositol hexakisphosphate (IP6) (Jiang et al., 2013). Proteins were separated by SDS-PAGE, transferred onto PVDF membranes and acetylation detected by autoradiography. As a loading control, an equivalent volume of the same samples was stained with Coomassie blue.

\section{In vitro kinase assay}

For in vitro kinase assays, $1 \mu \mathrm{g}$ of GST-MKK7, GST$\mathrm{MKK}^{\mathrm{K} 74 \mathrm{R}}$, or GST-MKK7 ${ }^{\mathrm{K} 167 \mathrm{R}}$ were incubated into phosphorylation buffer containing $50 \mathrm{mM}$ Tris- $\mathrm{HCl} \mathrm{pH} 7.4,5 \mathrm{mM}$ $\mathrm{MnCl}_{2}, 5 \mathrm{mM} \mathrm{MgCl}, 1 \mathrm{mM}$ DTT, $1 \mu \mathrm{M}$ cold ATP and $5 \mu \mathrm{Ci}$ $\left[\gamma^{32} \mathrm{P}\right]$-ATP (Perkin Elmer, USA) for $30 \mathrm{~min}$ at $30^{\circ} \mathrm{C}$. The reaction was stopped by adding Laemmli buffer and boiling at $95^{\circ} \mathrm{C}$ for $5 \mathrm{~min}$. Next, $10 \mu \mathrm{l}$ of each sample were separated by SDSPAGE, and phosphorylation detected by autoradiography. As a loading control, $10 \mu \mathrm{l}$ of the same samples were separated by SDS-PAGE and stained with Coomassie blue.

\section{Results}

\section{HopZ1a interacts with MKK7 in planta}

Considering published evidence, we decided to investigate MKK7 as a potential target for HopZ1a, using Agrobacteriummediated transient expression in $N$. benthamiana. As expression of MKK7 triggers cell death in N. benthamiana (Popescu et al., 2009), we used a catalytically inactive version of this protein $\left(\mathrm{MKK}^{\mathrm{K} 74 \mathrm{R}}\right)$ lacking kinase activity due to a defect on ATP binding (Dai et al., 2006; X. Zhang et al., 2007). For HopZ1a, we used both the wild-type version and a catalytically inactive version $\left(\mathrm{HopZ1} \mathrm{a}^{\mathrm{C} 216 \mathrm{~A}}\right.$ ) that lacks acetyltransferase activity and does not trigger cell death when transiently expressed in planta (Ma et al., 2006; Lewis et al., 2008, 2013; Jiang et al., 2013).

We first co-expressed MKK $7^{\mathrm{K} 74 \mathrm{R}}$-HA (or GFP-HA, as a control) with either HopZ1a-3xFLAG or HopZ1 ${ }^{\mathrm{C} 216 \mathrm{~A}}-3 \mathrm{xFLAG}$ in $N$. benthamiana leaves and performed co-immunoprecipitation (co-IP) using anti-HA beads. Both HopZ1a-3xFLAG and HopZ1a ${ }^{\mathrm{C} 216 \mathrm{~A}}-3 \mathrm{xFLAG}$ associated with $\mathrm{MKK} 7^{\mathrm{K} 74 \mathrm{R}}-\mathrm{HA}$, but not with the GFP-HA control (Fig. 1a). Expression of wild-type HopZ1a, but not HopZ1a ${ }^{\mathrm{C} 216 \mathrm{~A}}$, eventually triggered cell death in $N$. benthamiana, at variance with a recent report (Baudin et al., 2017), a difference that is likely to be due to higher expression levels being achieved in our experimental settings. Therefore, we decided to confirm the interaction detected by co-IP using only HopZ1a ${ }^{\mathrm{C} 216 \mathrm{~A}}$, to benefit from a wider sampling time range. To this end, we performed split-luciferase complementation assays (Fig. 1b), in which MKK7 ${ }^{\mathrm{K} 74 \mathrm{R}}$ and HopZ1 ${ }^{\mathrm{C} 216 \mathrm{~A}}$ were fused to the C-terminal (cluc) or $\mathrm{N}$-terminal (nluc) domains of the luciferase protein, respectively (Table 1 ). As a negative control, we used the P. syringae effector HopAF1, which, as HopZ1a, is associated with the plasma membrane through acylation (Lewis et al., 2008; Washington et al., 2016). The results showed a strong luminescence signal in tissues expressing $\mathrm{MKK} 7{ }^{\mathrm{K} 74 \mathrm{R}}$-cluc and HopZ1a ${ }^{\mathrm{C} 16 \mathrm{~A}}$-nluc, and only a background signal for MKK $7^{\mathrm{K} 74 \mathrm{R}}$-cluc and HopAF1-nluc (Fig. 1b), confirming the interaction between MKK7 and HopZ1a. To further analyse the direct interaction between $M K K 7^{\mathrm{K} 74 \mathrm{R}}$ and HopZ1a in planta, we used FRET-FLIM with HopZ1 ${ }^{\mathrm{C} 216 \mathrm{~A}}$ fused to GFP and $M K K 7^{\mathrm{K} 74 \mathrm{R}}$ fused to RFP. The GFP fluorescence lifetime for HopZ1a ${ }^{\mathrm{C} 216 \mathrm{~A}}-\mathrm{MKK} 7^{\mathrm{K} 74 \mathrm{R}}$ co-expression was significantly shorter than that of the control samples, supporting a direct interaction 
(a)

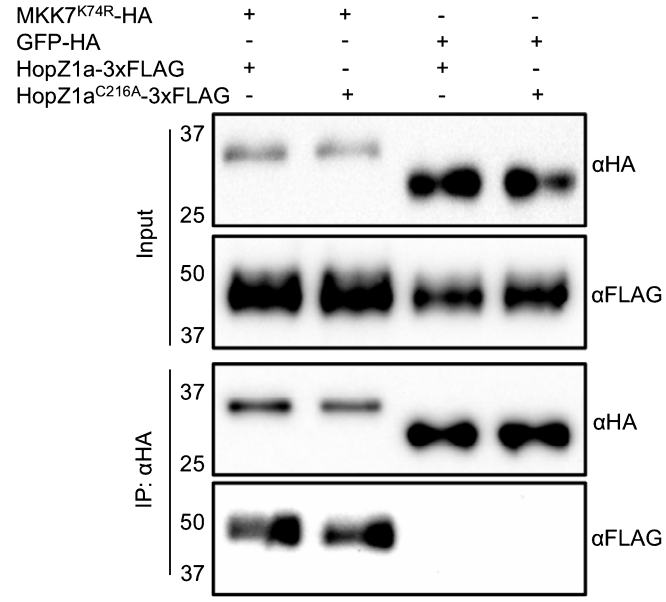

(b)
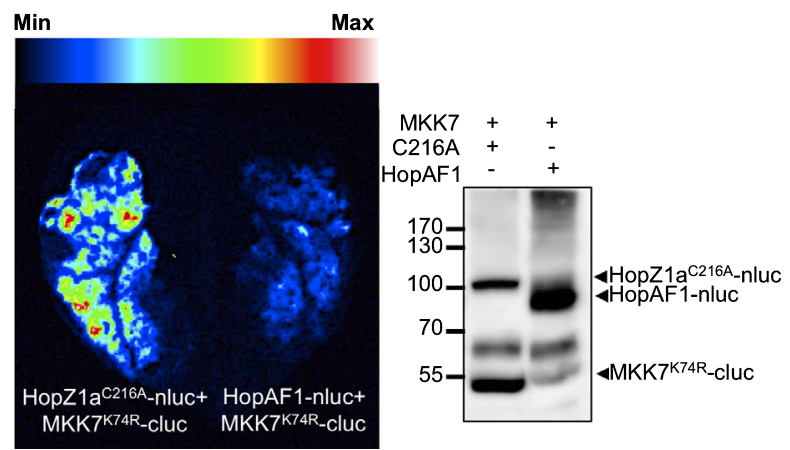

(c)

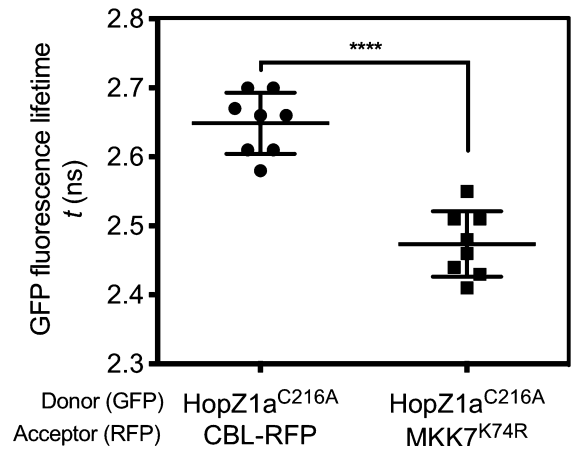

between MKK7 and HopZ1a (Fig. 1c). Confocal imaging showed MKK7 co-localisation with HopZ1a in the plasma membrane or its immediate vicinity, by contrast with MKK4/5 that displayed nuclear localisation (Supporting Information Fig. S1).

\section{AtMKK7 participates in flg22-triggered ROS burst, MAPK activation and callose deposition}

AtMKK7 activity has been linked to basal resistance (X. Zhang et al., 2007). As HopZ1a blocks the production of ROS upon recognition of the bacterial PAMP flagellin (Lewis et al., 2014), we investigated whether $M K K 7$ was expressed in Arabidopsis in response to the flagellin elicitor peptide flg22 (Fig. S2a). Results indicated that $\mathrm{flg} 22$ induced endogenous expression of $M K K 7$
Fig. 1 HopZ1a interacts with MKK7 in planta. (a) Co-immunoprecipitation assays using anti-HA beads. Nicotiana benthamiana leaves were coinoculated with a 1:1 mix of Agrobacterium tumefaciens carrying the indicated constructs. At $24 \mathrm{~h}$ after infiltration, leaves were treated with $10 \mu M$ DEX. Samples were taken $6 \mathrm{~h}$ after DEX treatment and proteins were extracted and incubated with anti-HA conjugated beads. The immunoprecipitated proteins were resolved by SDS-PAGE and analysed by Western blot with the indicated antibodies. The experiment was repeated three times with similar results. (b) Split-luciferase complementation assay in $N$. benthamiana. Leaves were co-inoculated with a 1:1 mixture of A. tumefaciens containing MKK $7^{\mathrm{K} 74 \mathrm{R}}$-cluc with either HopZ1 $\mathrm{a}^{\mathrm{C} 216 \mathrm{~A}}$-nluc or HopAF1-nluc as a negative control. Luminescence was quantified $48 \mathrm{~h}$ post inoculation (hpi) and protein accumulation was determined by immunoblotting using anti-luciferase antibody. The experiment was repeated three times with similar results. (c) FRET-FLIM assay using $N$. benthamiana leaves inoculated with a 1:1 mixture of $A$. tumefaciens containing the indicated constructs. HopZ1 $\mathrm{a}^{\mathrm{C} 216 \mathrm{~A}}$-GFP was used as donor protein and MKK $7^{K 74 R}$-RFP or calcineurin B-like protein-RFP (CBL-RFP, negative control) as acceptor protein. Images were taken at 24-30 hpi. Lines represent average values $(n=8)$ and error bars represent SE. Asterisks indicate significant differences as established by Student's test $(P<0.0001)$. Individual values are also shown. The experiment was repeated three times with similar results.

(Fig. S2a). Then, we used transgenic Arabidopsis plants expressing the $A t M K K 7$ gene under the control of the dexamethasone (DEX)-inducible promoter, from this point forwards $M K K 7$ DEX plants (Figs S2b, S3; Methods S1; X. Zhang et al., 2007), to assay ROS production in response to flg22. flg22-triggered ROS burst was significantly stronger in plants overexpressing $M K K 7$, but not $\mathrm{MKK} 7^{\mathrm{K} 74 \mathrm{R}}$ (Figs 2a, S4a), suggesting that MKK7 contributes to flg22-triggered ROS production in a kinase activity-dependent manner. We also analysed ROS production in plants expressing an antisense $M K K 7$ transgene under the control of a $35 \mathrm{~S}$ promoter (from this point forwards, asMKK7 plants), in which $M K K 7$ expression is specifically compromised (Dai et al., 2006; Fig. S2c-f), ROS production after flg22 treatment on asMKK7 transgenic plants was significantly weaker than that observed in flg22-treated Col-0 plants (Figs 2b, S4b). flg22-induced ROS production on mkk7 mutant plants (Fig. S5c; Methods S2) was consistent with that displayed by asMKK7 plants (Fig. S4b). Altogether, these results indicated that MKK7 is involved in flg22-triggered ROS production.

PRR recognition of bacterial PAMPs leads to the activation of MAPK cascades (Boller \& Felix, 2009). Transgenic expression of HopZ1a in Arabidopsis suppresses flg22-triggered phosphorylation of MPK3 and MPK6 (Lewis et al., 2014). Interestingly, the flg22-triggered activation of MPK3, MPK6 and MPK4/11 was accelerated and enhanced in plants overexpressing MKK7 (Fig. 2c), while it was abolished in plants expressing as $M K K 7$ (Fig. 2d), indicating that MKK7 contributes to flg22-triggered MAPK activation. MAP kinase activation on $m k k 7$ mutant plants was consistent with that displayed by asMKK7 plants (Fig. S5b).

As a late PTI response, we monitored flg22-triggered callose deposition. In agreement with the above-mentioned results, flg22-triggered deposition of callose was enhanced upon $M K K 7$ overexpression (Fig. 2e). Accumulation of callose in flg22-treated asMKK7 plants was significantly lower than flg22-treated, but 
(a)

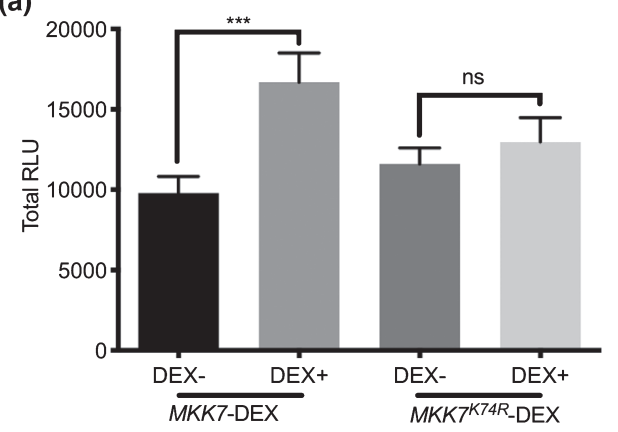

(c)
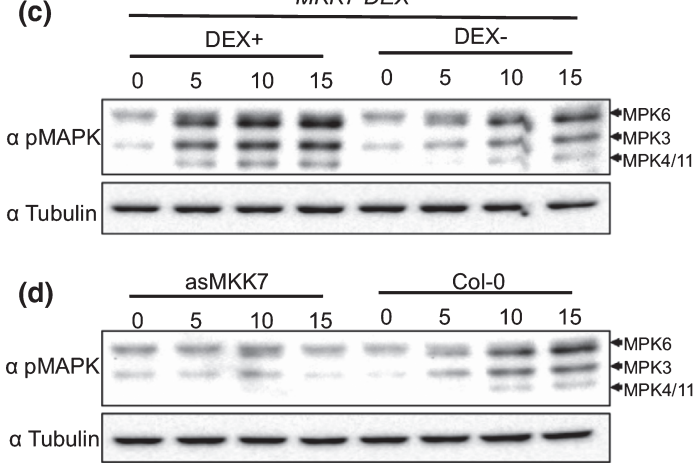

(b)

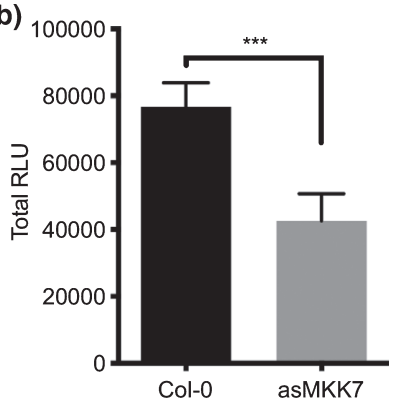

(e)

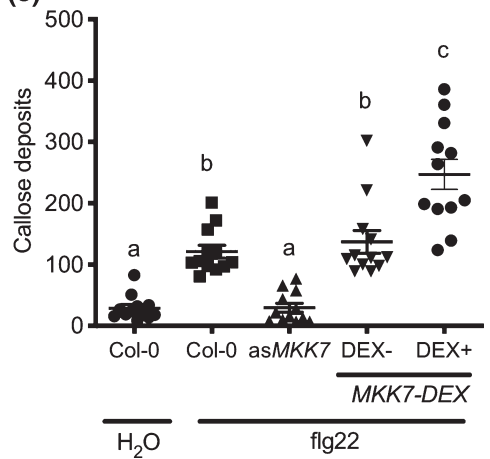

Fig. 2 AtMKK7 participates in flg22-triggered defence response. $(\mathrm{a}, \mathrm{b})$ ROS production after treatment with $100 \mathrm{nM}$ flg22 of MKK7-DEX and MKK $7^{\text {K74R }}$ DEX plants (a) or Col-0 and asMKK7 plants (b), measured in a luminol-based assay and represented as relative luminescence units (RLU). MKK7-DEX and MKK $7^{\text {K74R }}$-DEX plants were treated either with a DEX or mock solution $24 \mathrm{~h}$ before flg22 treatment. Graphs show accumulated RLU production over $40 \mathrm{~min}$ after $100 \mathrm{nM}$ flg22 treatment. Error bars represent SE $(n=20)$. Asterisks indicate significant differences compared with the control as established by Student's $t$-test $(P \leq 0.001)$. (c, d) MAP kinase activation assay after $100 \mathrm{nM}$ flg22 treatment. Samples were taken at four different time points $(0,5,10$ and $15 \mathrm{~min}$, as indicated) after treatment with $100 \mathrm{nM}$ flg22. MAPK phosphorylation was detected by Western blot analysis. Anti-tubulin was used as loading control. In (c), plants were pretreated with either a DEX or mock solution $24 \mathrm{~h}$ before flg22 treatment. (e) Quantification of callose deposits after flg22 treatment. MKK7-DEX plants were infiltrated with either DEX (DEX+) or mock solution (DEX-) as indicated in the figure. At $24 \mathrm{~h}$ later, MKK7-DEX plants, asMKK7 plants, and Col-0 control plants were infiltrated with $100 \mathrm{nM}$ flg22. Col-0 plants were also infiltrated with water (negative control). At $18 \mathrm{~h}$ after treatment, leaves were stained with aniline blue and observed under ultraviolet (UV) fluorescence microscope. Lines represent average values $(n=12)$ and error bars represent SE. Individual values are also shown. Statistical differences were determined using one-way ANOVA $(\alpha=0.05)$ with Tukey's multiple comparisons test and different letters indicate statistical significance. The experiment was repeated three times with similar results.

not $\mathrm{H}_{2} \mathrm{O}$-treated, control plants (Fig. 2e). Our results showed that MKK7 contributes to the onset of PTI.

\section{MKK7 contributes to the basal defence against $P$. syringae pv tomato}

Plant recognition of bacterial PAMPs leads to the restriction of bacterial growth (Zipfel et al., 2004). MKK7 contribution to plant defence against bacterial pathogens has been previously shown by monitoring the effect of MKK7 overexpression, or MKK7 silencing in Arabidopsis plants inoculated with P. syringae pv maculicola or Xanthomonas campestris (X. Zhang et al., 2007). We found that Arabidopsis plants overexpressing MKK7 also displayed enhanced resistance to Pto DC3000 (Fig. 3a), whereas asMKK7 plants showed enhanced susceptibility compared with their respective control plants (Fig. 3b). Susceptibility to infection was also enhanced in $m k k 7$ mutant plants (Fig. S5d). Additionally, we analysed growth of a Pto DC3000 $\Delta \mathrm{hrcV}$ mutant strain, which lacked a functional T3SS and could not suppress activation of PTI, and is consequently nonpathogenic in Arabidopsis. Growth of Pto $\Delta h r c V$ mutant bacteria in MKK7overexpressing plants was less than half of that achieved in control plants (Fig. 3c). Taken together, these results demonstrated that MKK7 is involved in the activation of basal defences that limit Pto DC3000 colonisation of Arabidopsis.

\section{MKK7 participates in AvrRpt2-triggered disease resistance in Arabidopsis}

Expression of MKK7 is induced in Arabidopsis by inoculation of Pto DC3000 expressing the heterologous effector AvrRpt2 (X. Zhang et al., 2007). Modification of RIN4 by AvrRpt2 triggers RPS2-mediated ETI that restricts bacterial growth (Axtell \& Staskawicz, 2003; Mackey et al., 2003). To investigate whether MKK7 participates in AvrRpt2-triggered immunity signalling, we measured the effect of MKK7 silencing on attenuation of bacterial growth of DC3000 expressing AvrRpt2. To this purpose, we performed competitive index (CI) assays 
(a)

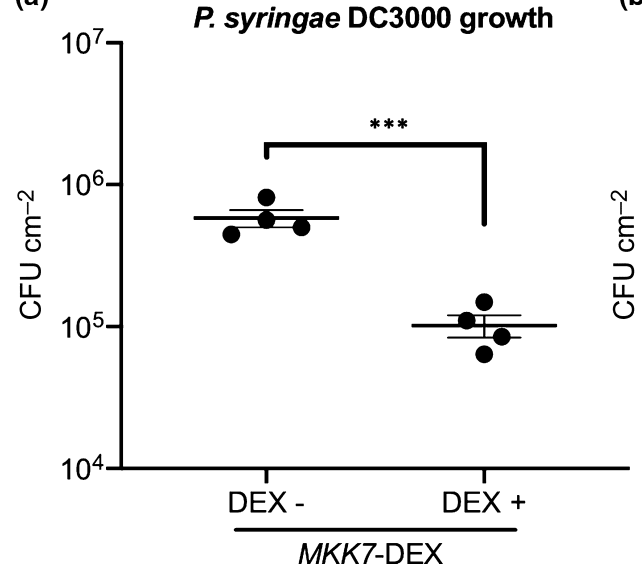

(b)

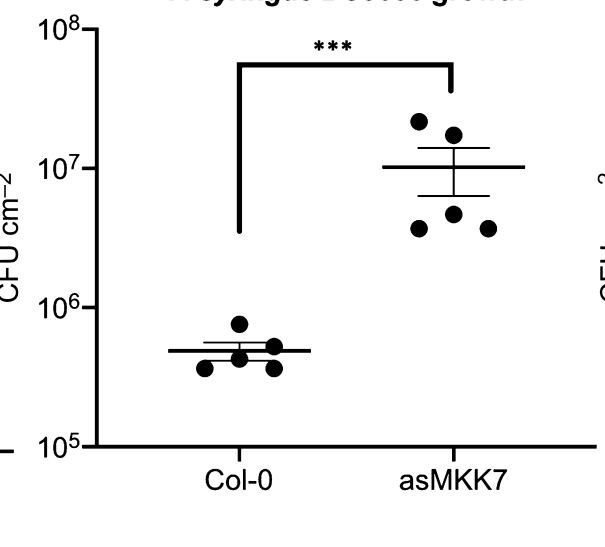

(c)

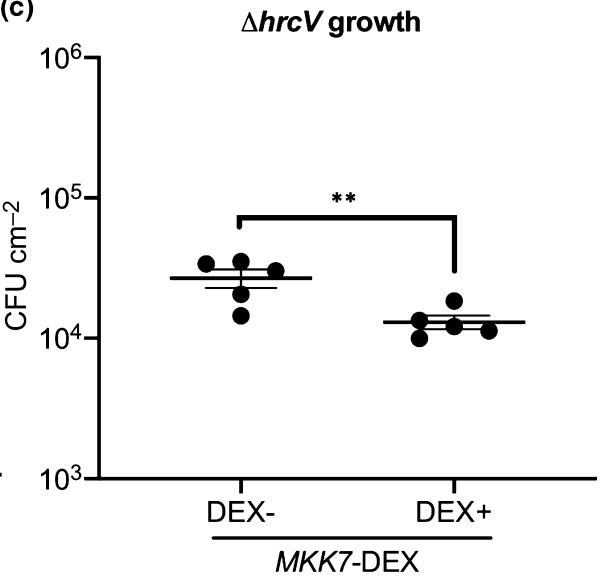

Fig. 3 AtMKK7 expression restricts bacterial growth. Bacterial multiplication assay in MKK7-DEX (a, c) or Col-0 and asMKK7 (b) plants. Leaves were syringe infiltrated with a $5 \times 10^{4} \mathrm{CFU} \mathrm{m}{ }^{-1}$ suspension of Pto DC3000 (a, b) or Pto $\Delta h r \mathrm{CV}(\mathrm{c})$, as indicated in each graph. MKK7-DEX plants were treated with either DEX (DEX+) or Mock solution (DEX-) $2 \mathrm{~h}$ before bacterial inoculation. The graphs show bacterial titres at $4 \mathrm{dpi}$. Lines represent mean values and error bars represent standard error $(n=5)$. Individual values are also shown. Asterisks indicate significant differences as established by Student's $t$-test with the null hypothesis of mean values not significantly different $(* *, P<0.01 ; * * *, P<0.001)$.

(Macho et al., 2016) by co-inoculating Pto DC3000 and Pto DC3000 expressing AvrRpt2, in both Col-0 and asMKK7 Arabidopsis plants (Fig. 4a). The CI was calculated as the Pto DC3000AvrRpt2/ Pto DC3000 ratio in the output sample, divided by this ratio within the inoculum (input), which should be close to one. As previously described for Col-0 wild-type plants (Macho et al., 2007), the CI of Pto DC3000 expressing AvrRpt 2 was significantly smaller than one, showing a clear growth attenuation associated with AvrRpt2 expression. However, in a similar assay carried out in asMKK7 plants, the CI obtained was 10-fold higher and close to one, indicating that Pto DC3000 bacteria expressing AvrRpt2 multiply in these plants to levels similar to those of Pto DC3000 (Fig. 4a). By contrast, ZAR1-mediated growth attenuation of Pto DC3000 expressing HopZ1a in Col-0 wild-type plants was not significantly altered in asMKK7 plants (Fig. 4a). Taken together, these results indicated that $\mathrm{MKK} 7$ has a strong contribution to RPS2-mediated immunity, which is SA-dependent, but is not involved in SA-independent ZAR1-mediated immunity.

The results obtained quantifying bacterial multiplication within mixed infections were supported by measuring ion leakage from plant tissues, indicative of the activation of HR-associated cell death. In wild-type plants, samples inoculated with Pto DC3000 expressing AvrRpt2 displayed the highest conductivity at all time points, consistent with the induction of $\mathrm{HR}$, while samples inoculated with Pto DC3000 displayed the lowest, consistent with a compatible interaction, as expected (Fig. 4b). Interestingly, in asMKK7 plants, samples inoculated with Pto DC3000 displayed conductivity levels indistinguishable from those inoculated with Pto DC3000 expressing AvrRpt2, and only slightly higher than those inoculated with DC3000 in wild-type plants (Fig. 4b), therefore confirming that MKK7 has a strong contribution on RPS2-mediated immunity. Results obtained in conductivity assays performed with HopZ1a-expressing bacteria in Col-0 and asMKK7 plants (Fig. 4c) were consistent with those obtained for HopZ1a in bacterial multiplication experiments (Fig. 4a).

\section{HopZ1a suppresses MKK7-dependent basal defence signalling in Arabidopsis}

To analyse whether HopZ1a activity suppresses MKK7dependent defence signalling in Arabidopsis, we investigated whether HopZ1a expression from Pto DC3000 was able to rescue the growth attenuation caused by MKK7-overexpression (Fig. 5). To circumvent the ETI triggered by HopZ1a on the Col-0 background, we generated MKK7-DEX transgenic plants on the zar1-1 knockout mutant background, in which HopZ1a does not trigger immunity (Lewis et al., 2010). Expression of HopZ1a from Pto DC3000 suppressed the attenuation of bacterial growth caused by MKK7 overexpression (Fig. 5a), supporting the idea that MKK7 is a relevant target for HopZ1a virulence activity. To determine whether bacteria-delivered HopZ1a is able to suppress MKK7-associated PTI responses, we used Pseudomonas fluorescens strain Pf55 (from this point forwards Pf55), a nonpathogenic strain expressing a heterologous functional T3SS (Jamir et al., 2004). Inoculation with Pf55 resulted in the accumulation of callose, noticeably higher in MKK7-overexpressing plants (Fig. 5b). However, HopZ1a expression from Pf55 inhibited callose deposition, and even abolished the enhanced accumulation caused by MKK7 overexpression (Fig. 5b), indicating that HopZ1a is sufficient to suppress MKK7-mediated callose deposition. Last, we analysed whether HopZ1a was able to suppress MKK7dependent PR1 accumulation. Overexpression of MKK7 induces PR1 gene expression (X. Zhang et al., 2007). Accordingly, MKK7-overexpressing plants treated with water (as mock control) or inoculated with Pf55 displayed local PR1 accumulation in the inoculated tissues (Fig. 5c). Noticeably, local PR1 accumulation was completely abolished in plants inoculated with Pf55 expressing the HopZ1a effector protein (Fig. 5c), indicating that 

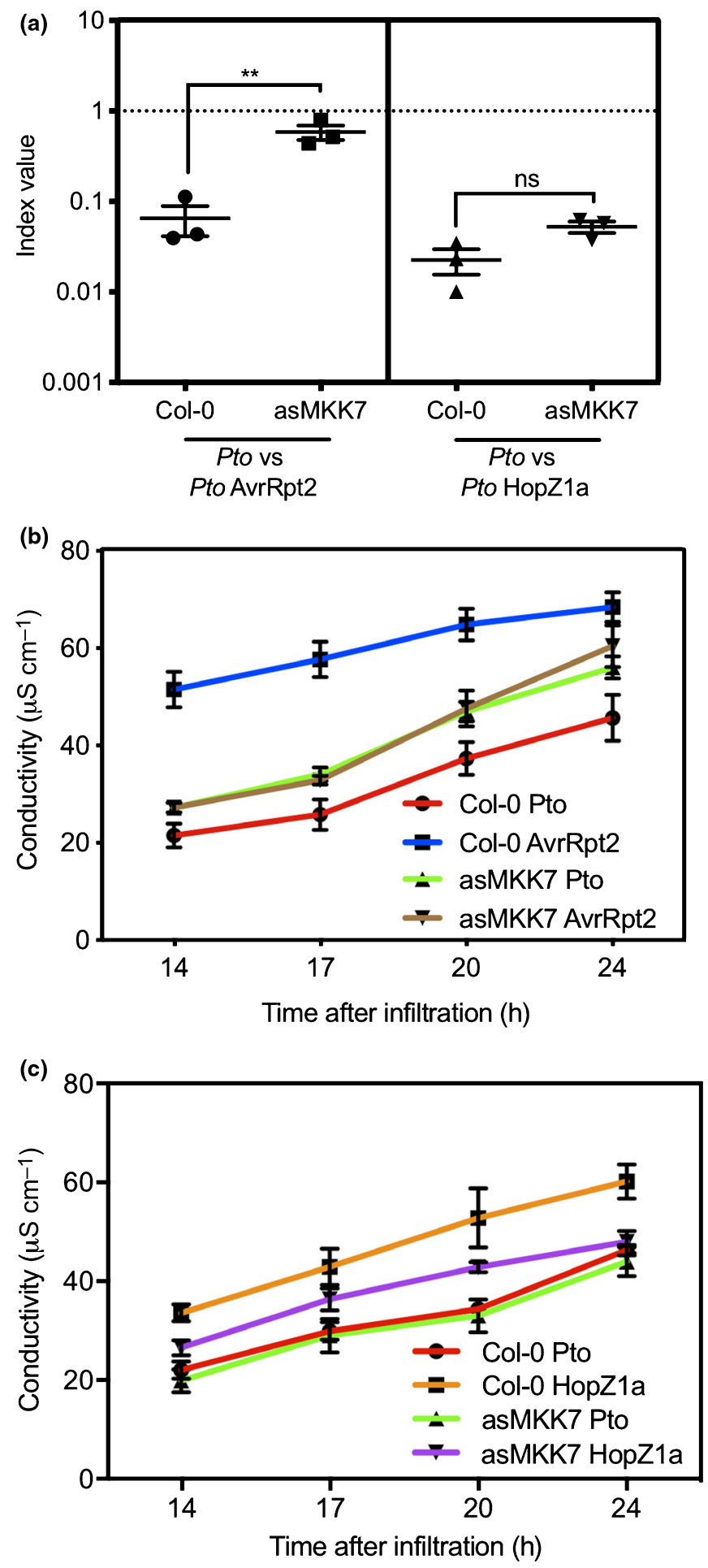

HopZ1a is also capable of suppressing MKK7-dependent PR1 accumulation.

\section{MKK7-dependent SAR is suppressed by HopZ1a}

MKK7 participates in SAR signalling in Arabidopsis after Pto DC3000 inoculation (X. Zhang et al., 2007). As HopZ1a
Fig. 4 AtMKK7 participates in AvrRpt2-mediated ETI defence response. (a) Competitive index (Cls) measuring bacterial proliferation in Col-0 or asMKK7 plants. Arabidopsis leaves were inoculated with a $1: 1$ mix of either Pto expressing AvrRpt2 and Pto DC3000 or Pto expressing HopZ1a and Pto DC3000 at $5 \times 10^{4} \mathrm{CFU} \mathrm{m}{ }^{-1}$. Bacterial loads were determined $4 \mathrm{~d}$ post inoculation (dpi). Cls are calculated as the output ratio between the strain expressing the effector and the corresponding wild-type or mutant strain, divided by their input ratio. Each $\mathrm{Cl}$ mean represents three biological replicates per treatment. Individual values are shown. Error bars represent the $\mathrm{SE}$, and asterisks indicate significant differences as established by Student's $t$-test $(P<0.01)$ and the null hypothesis: mean index is not significantly different from 1 ; ns, not significant. Results presented are representative of three independent experiments. (b) Ion leakage assays in Col-0 and asMKK7 Arabidopsis leaves inoculated with a $5 \times 10^{7} \mathrm{CFU} \mathrm{ml}^{-1}$ suspension of Pto DC3000 or Pto expressing AvrRpt2. (c) lon leakage assays in Col-0 and asMKK7 Arabidopsis leaves inoculated with a $5 \times 10^{7} \mathrm{CFU} \mathrm{ml}{ }^{-1}$ suspension of Pto DC3000 or Pto expressing HopZ1a. $(b, c)$ Conductivity was measured at the indicated time points. Lines represent mean values. Error bars represent SE $(n=3)$.

suppresses SAR (Macho et al., 2010), we investigated whether HopZ1a suppresses MKK7-dependent SAR. We used Arabidopsis MKK7-DEX leaves, either (locally) treated with DEX or not, $2 \mathrm{~h}$ before carrying out a primary (local) inoculation in these same leaves with a $P$. syringae Pf55 strain constitutively expressing HopZ1a from a stable plasmid (Fig. 6). At $3 \mathrm{~d}$ later, we performed a secondary infection on distal (systemic) leaves with a fully virulent strain (Pto DC3000) (Fig. 6a) or extracted proteins to quantify systemic PR1 accumulation in distal (systemic) noninoculated leaves (Fig. 6b). Systemic leaves were not treated with DEX at any point. We finally quantified bacterial multiplication on systemic, secondary infection sites as a direct and biologically relevant measurement of SAR (Fig. 6a). As controls, we also performed inoculation at primary sites using either infiltration buffer only (mock inoculation) or Pf55 not expressing the HopZ1a gene. While systemic multiplication of Pto DC3000 was significantly reduced in MKK7-DEX-induced plants that had been either mock-inoculated in primary (local) leaves, or inoculated with Pf55 (Fig. 6a), in plants inoculated in primary (local) leaves with HopZ1a-expressing Pf55, multiplication of Pto DC3000 in secondary (distal) sites was maintained up to levels similar to those reached in control noninduced MKK7-DEX plants. Furthermore, PR1 accumulation in secondary, systemic sites of infection was suppressed only in those plants that had been previously inoculated in primary (local) leaves with the HopZ1aexpressing Pf55 strain (Fig. 6b). Taken together, these results indicated that HopZ1a is capable of suppressing the SAR response specifically triggered through MKK7 expression. To determine a molecular connection between MKK7 and SAR, and to confirm that such connection can be suppressed by HopZ1a, we performed quantitative analysis of AGD2-LIKE DEFENSE RESPONSE PROTEIN 1 (ALDI) expression by qRT-PCR on samples obtained from DEX-induced or noninduced MKK7DEX zar1-1 plants, either mock-inoculated, infiltrated with Pf55, or infiltrated with Pf-55 expressing HopZ1a (Fig. 6c). ALD1 expression is essential for SAR (Song et al. 2004; Cecchini et al., 2015). Results showed that $A L D 1$ expression was increased in DEX-induced plants, both mock-infiltrated and Pf-55- 

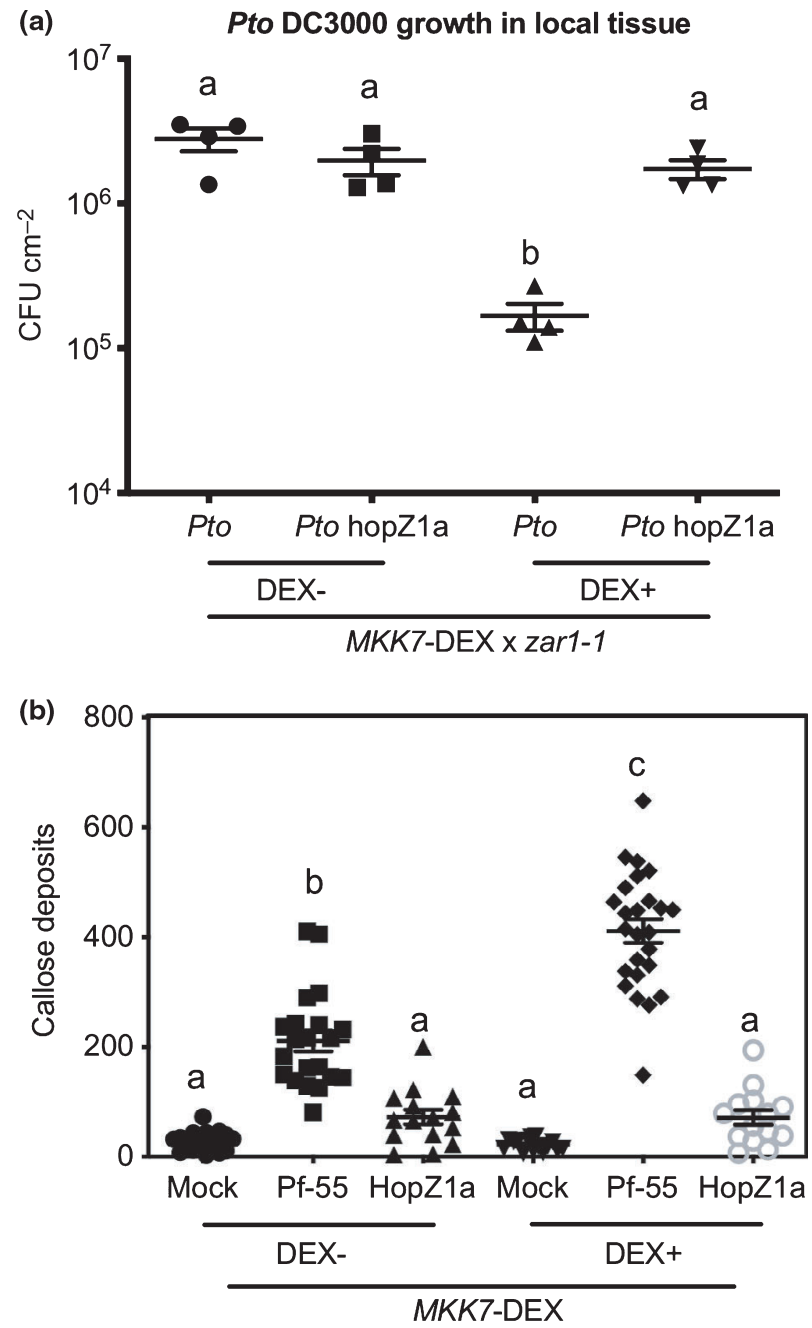

(c)

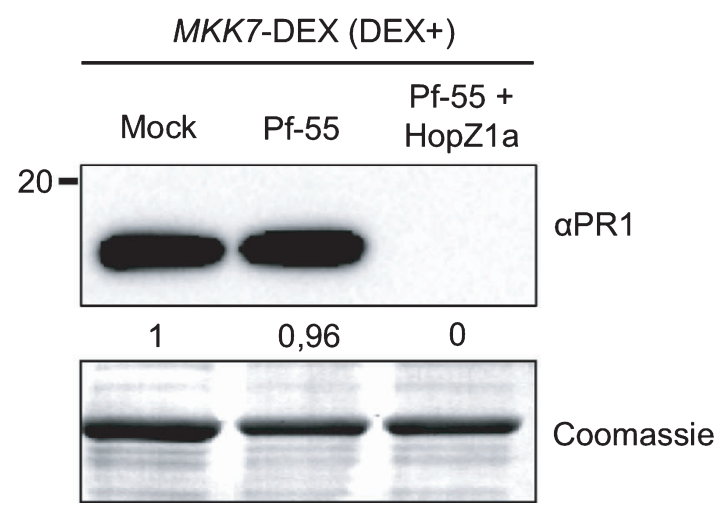

infiltrated, but that increase in $A L D 1$ expression was suppressed in plants infiltrated with Pf-55 expressing HopZ1a.

\section{HopZ1a acetylates MKK7 in vitro and in planta}

HopZ1a functions as an acetyltransferase capable of strong autoacetylation in vitro (Lee et al., 2012; Ma et al., 2015), and of transacetylation of some of its interacting partners in the plant (Lee et al., 2012; Jiang et al., 2013; Lewis et al., 2013; Bastedo et al., 2019; Lee et al., 2019).
Fig. 5 HopZ1a interferes in the MKK7 defence activation pathway. (a) Bacterial multiplication assay in MKK7-DEX x zar1-1 plants. Leaves were infiltrated with either DEX (DEX+) or Mock solution (DEX-). At $2 \mathrm{~h}$ after treatment, leaves were infiltrated with a $5 \times 10^{4} \mathrm{CFU} \mathrm{ml^{-1 }}$ suspension of either Pto DC3000 or Pto DC3000 expressing HopZ1a. The graphs show bacterial titres at $4 \mathrm{~d}$ post inoculation (dpi). Lines represent mean values and error bars represent SE $(n=4)$. Individual values are shown. Statistical differences were determined using one-way ANOVA $(\alpha=0.05)$ with Tukey's multiple comparisons test and different letters indicate statistical significance. (b) Quantification of callose deposits in MKK7-DEX plants pretreated with either DEX (DEX+) or mock solution (DEX-). At $24 \mathrm{~h}$ after treatment, the same leaves were infiltrated with $10 \mathrm{mM} \mathrm{MgCl}_{2}$ (mock), $5 \times 10^{5} \mathrm{CFU} \mathrm{ml}^{-1}$ suspension of Pf-55 (empty vector) or a

$5 \times 10^{5} \mathrm{CFU} \mathrm{ml}^{-1}$ suspension Pf-55 expressing HopZ1a. At $18 \mathrm{~h}$ after bacterial inoculation, leaves were stained with aniline blue and observed under UV fluorescence microscope. Lines represent average values $(n=24)$ and error bars represent SE. Individual values are shown. Statistical differences were determined using one-way ANOVA $(\alpha=0.05)$ with Tukey's multiple comparisons test and different letters indicate statistical significance. (c) PR1 levels in MKK7-DEX $\times$ zar1-1 plants pretreated with either DEX (DEX+) or mock solution (DEX-) were detected by Western blot analysis. At $2 \mathrm{~h}$ after treatment, same leaves were infiltrated with $10 \mathrm{mM} \mathrm{MgCl}_{2}$ (mock), $5 \times 10^{5} \mathrm{CFU} \mathrm{ml}^{-1}$ suspension of Pf-55 (empty vector) or a $5 \times 10^{5} \mathrm{CFU} \mathrm{ml} \mathrm{m}^{-1}$ suspension Pf-55 expressing HopZ1a. Samples were taken at $48 \mathrm{~h}$ post inoculation (dpi). Coomassie staining is shown as the loading control.

To determine whether HopZ1a is able to acetylate MKK7, we performed a ${ }^{14} \mathrm{C}$-labelled acetyl-coenzyme A (acetyl-CoA) transferase reaction in vitro, in the presence of MKK7 and either HopZ1a or HopZ1 a ${ }^{\text {C216A }}$. As previously described, HopZ1a was strongly autoacetylated, while HopZ1a ${ }^{\mathrm{C} 216 \mathrm{~A}}$ was not (Figs 7a, S6a). More importantly, MKK7 was acetylated in the presence of HopZ1a, but not in the presence of HopZ1 ${ }^{\mathrm{C} 216 \mathrm{~A}}$ (Figs 7a, S6a), suggesting that HopZ1a acetylates MKK7 in vitro in a manner dependent on the integrity of its catalytic site. We also analysed the acetyltransferase activity of HopZ1 ${ }^{\text {K289R }}{ }^{\text {, a mutant that has }}$ been described to display reduced transacetylation activity (Ma et al., 2015). Interestingly, MKK7 was not acetylated in the presence of HopZ1a ${ }^{\text {K289R }}$ (Fig. S6a), suggesting that K289 contributes to HopZ1a transacetylation activity of MKK7.

HopZ1a acetylation of the Arabidopsis pseudokinase ZED1, a decoy/adaptor involved in ZAR1-dependent HopZ1a-triggered immunity, takes place on threonine residues in positions 125 and 177 of its amino acid sequence (Lewis et al., 2013), with T177 located within the catalytic loop (Fig. S7c). The catalytic loop constitutes a conserved domain that in active kinases includes the proton acceptor motif (HRD) essential for kinase activity (Lewis et al., 2013; Fig. S7a,c). However, the catalytic loop of MKK7 lacks threonine residues (Fig. S7a,c). Interestingly, VopA, another effector from the YopJ family, modifies a lysine within the catalytic loop of its mammalian target MKKs, disrupting ATP binding and inactivating the kinase (Trosky et al., 2007). Therefore, we reasoned that highly conserved lysine K167, located within the catalytic loop of MKK7 (Fig. S7a,c) was a good candidate for HopZ1a acetylation.

To test K167 potential relevance for HopZ1a interference with MKK7 activity, we introduced a point mutation into MKK7 by substituting K167 with an arginine to generate mutant 

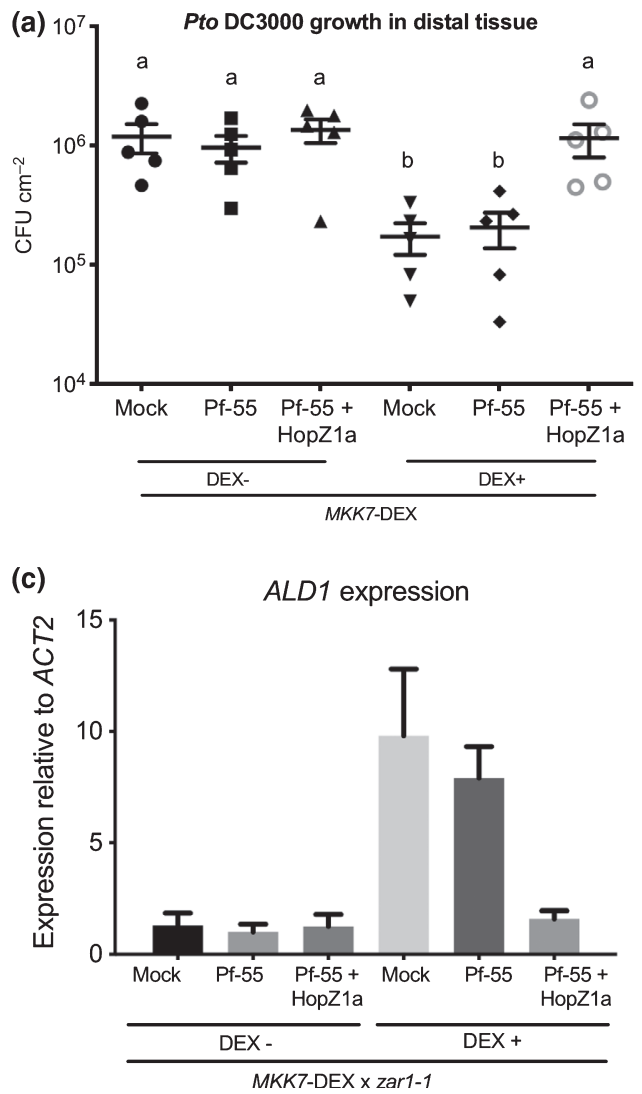

(b)

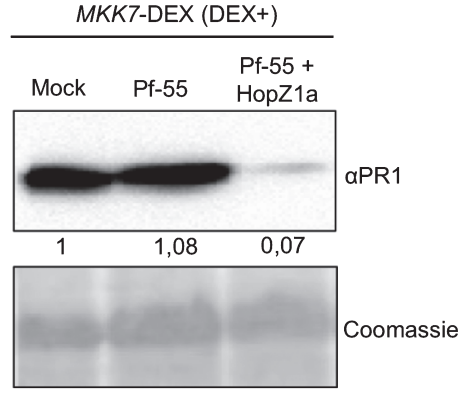

Fig. 6 HopZ1a suppresses AtMKK7-triggered SAR. (a) Bacterial multiplication assay in distal leaves of MKK7-DEX plants preinoculated with the indicated strains. Leaves were first infiltrated with either DEX (DEX+) or Mock solution (DEX-). At $2 \mathrm{~h}$ later, same leaves were infiltrated with $10 \mathrm{mM} \mathrm{MgCl}{ }_{2}$ (mock), $5 \times 10^{5} \mathrm{CFU} \mathrm{ml}{ }^{-1}$ suspension of Pf-55 (empty vector) or a $5 \times 10^{5} \mathrm{CFU} \mathrm{ml}{ }^{-1}$ suspension of Pf- 55 expressing HopZ1a. At $3 \mathrm{~d}$ after primary inoculation, distal leaves were inoculated with a $5 \times 10^{4} \mathrm{CFU} \mathrm{ml}^{-1}$ suspension of Pto DC3000. Graph shows Pto DC3000 growth at $4 \mathrm{~d}$ post inoculation (dpi). Lines represent average values $(n=5)$ and error bars represent SE. Individual values are shown. Statistical differences were determined using one-way ANOVA $(\alpha=0.05)$ with Tukey's multiple comparisons test and different letters indicate statistical significance. (b) PR1 accumulation in distal leaves of MKK7-DEX plants described was analysed by Western blot analysis in plants inoculated with the indicated strains. First, leaves were infiltrated with either DEX or mock solution. At $2 \mathrm{~h}$ later, the same leaves were infiltrated with $10 \mathrm{mM} \mathrm{MgCl}_{2}$ (mock), a $5 \times 10^{5} \mathrm{CFU} \mathrm{ml}^{-1}$ suspension of Pf-55 (empty vector) or a $5 \times 10^{5} \mathrm{CFU} \mathrm{ml}{ }^{-1}$ suspension of Pf-55 expressing HopZ1a. At $3 \mathrm{~d}$ after infiltration, distal leaves were collected. In total, $10 \mu \mathrm{g}$ of total protein were loaded per sample, and Coomassie staining is shown as loading control. Results presented are representative of three independent experiments. (c) Analysis of ALD1 gene expression on local leaves of MKK7-DEX zar1-1 plants preinoculated with the indicated strains. Leaves were first infiltrated with either DEX $\left(\mathrm{DEX}+\right.$ ) or Mock solution (DEX-). At $2 \mathrm{~h}$ later, the same leaves were infiltrated with $10 \mathrm{mM} \mathrm{MgCl}_{2}$ (mock), $5 \times 10^{5} \mathrm{CFU} \mathrm{ml}^{-1}$ suspension of Pf-55 (empty vector) or a $5 \times 10^{5} \mathrm{CFU} \mathrm{ml} \mathrm{m}^{-1}$ suspension of Pf-55 expressing HopZ1a. At $48 \mathrm{~h}$ after inoculation, local leaves were processed for quantitative analysis of ALD1 gene expression by qRT-PCR using primers listed in Table 3.

$\mathrm{MKK}^{\mathrm{K} 167 \mathrm{R}}$ and used this mutant protein as a substrate for HopZ1a acetylation in vitro. The assay showed that the mutation K167R prevents HopZ1a-mediated acetylation of MKK7 (Figs 7a, S6a), suggesting that K167 is a major target for HopZ1a acetylation.

Furthermore, we also assayed HopZ1a-dependent MKK7 acetylation in planta, by transient co-expression in $N$. benthamiana of all possible pair combinations of MKK7-3XFLAG or MKK7 ${ }^{\text {K167R }}-3$ XFLAG with GFP, HopZ1a-GFP or HopZ1a ${ }^{\mathrm{C} 216 \mathrm{~A}}$-GFP, followed by FLAG-IP and Western blot hybridisation using an anti-acetylated-lysine antibody (anti-AcK) (Fig. 7b). We detected a strong signal for acetylated MKK7 when the kinase was co-expressed with HopZ1a, while only a faint signal was detectable when MKK7 was expressed by itself or coexpressed with HopZ1a ${ }^{\text {C216A }}$ (Fig. 7b). Furthermore, when $\mathrm{MKK}^{\mathrm{K} 167 \mathrm{R}}$ was co-expressed with HopZ1a, only a weak acetylation signal was detected, suggesting that K167 is a major target for HopZ1a-dependent acetylation in planta (Fig. 7b). We also assayed $M K K 7^{\mathrm{K} 74 \mathrm{R}}$, showing that it is acetylated by HopZ1a to levels similar to those achieved for MKK7 (Fig. S6b), which suggests that autophosphorylation of MKK7 is not required for its acetylation by HopZ1a. An estimation of the relative acetylation efficiency was obtained by calculating the signal ratios of anti-AcK over 3XFLAG for each combination (Figs 7b, S6b).

\section{K167 is required for full MKK7 activity in vitro and in planta}

MKK7-dependent activation of plant immunity requires MKK7 kinase activity (X. Zhang et al., 2007). MKK7 autophosphorylation activity is absent in the $\mathrm{MKK} 7^{\mathrm{K} 74 \mathrm{R}}$ mutant, in which a lysine within the ATP binding pocket has been changed to arginine 
(a)

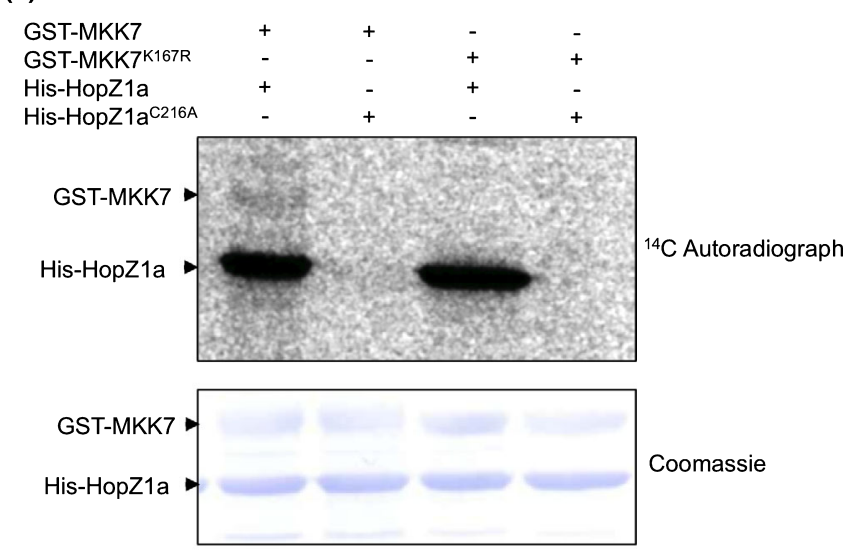

(b)

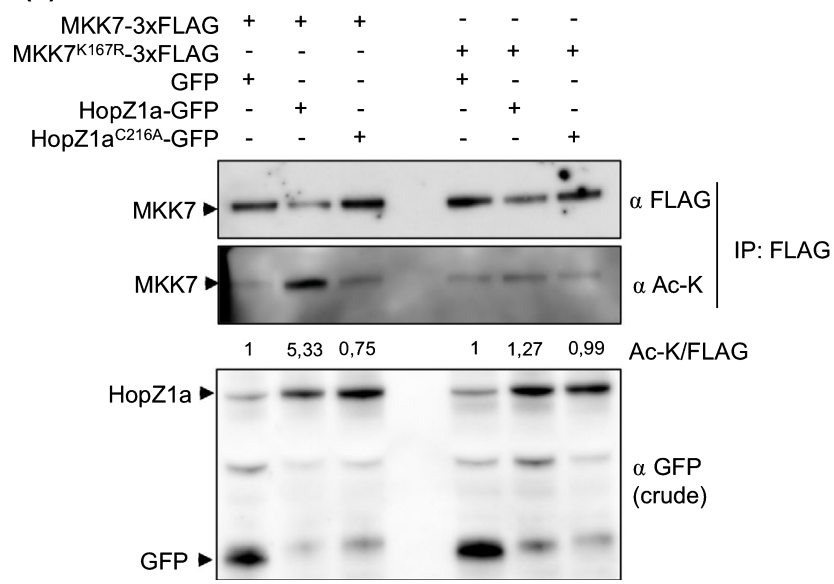

Fig. 7 HopZ1 a acetylates MKK7 in vitro and in planta. (a) In vitro acetylation assay. At $5 \mu \mathrm{g}$ of GST-MKK7 or GST-MKK $7^{\mathrm{K} 167 \mathrm{R}}$ were incubated with $3 \mu \mathrm{g}$ of $6 \times \mathrm{His}-\mathrm{HopZ1}$ a or $6 \times \mathrm{His}-\mathrm{HopZ1} \mathrm{a}^{\mathrm{C} 216 \mathrm{~A}}$ in acetylation buffer containing ${ }^{14} \mathrm{C}$-acetyl-CoA. Samples were separated by SDS-PAGE and proteins were transferred to a PVDF membrane. The membrane was exposed to an imaging plate for $1 \mathrm{wk}$ and acetylation was detected by autoradiography. Coomassie staining is shown as loading control. (b) In planta acetylation assay. Nicotiana benthamiana leaves were co-inoculated with a 1:1 mix of Agrobacterium tumefaciens carrying the indicated constructs. $24 \mathrm{~h}$ after infiltration, leaves were treated with $10 \mu \mathrm{M}$ DEX. Samples were taken $6 \mathrm{~h}$ after DEX treatment and proteins were extracted and incubated with anti-FLAG conjugated beads. The immunoprecipitated proteins were resolved by SDS-PAGE and analysed by Western blot with the indicated antibodies. The experiment was repeated three times with similar results.

(Dai et al., 2006). To determine whether K167 is necessary for MKK7 kinase activity, we carried out in vitro GST-MKK7, GST-MKK $7^{\mathrm{K} 74 \mathrm{R}}$, and GST-MKK $7^{\mathrm{K} 167 \mathrm{R}}$ autophosphorylation assays (Fig. 8a). Autophosphorylation was strongly reduced in the GST-MKK $7^{\text {K167R }}$ mutant version (Fig. 8a), and completely abolished in the control GST-MKK $7^{\mathrm{K} 74 \mathrm{R}}$ mutant version. We also detected a mobility shift in SDS-PAGE gels in GST-MKK7 samples, which displayed a slower migration rate suggestive of protein phosphorylation, and which was absent in both GST$\mathrm{MKK} 7^{\mathrm{K} 74 \mathrm{R}}$ and GST-MKK $7^{\mathrm{K} 167 \mathrm{R}}$ samples (Fig. 8b). These results indicated that $\mathrm{K} 167$ plays a key role in MKK7 kinase activity.
To confirm that K167 is key for MKK7 activity in planta, we expressed MKK7 and its derivatives $M K K 7^{\mathrm{K} 167 \mathrm{R}}$ and $\mathrm{MKK} 7^{\mathrm{K} 74 \mathrm{R}}$ in $N$. benthamiana leaves under the control of a constitutive promoter using Agrobacterium-mediated transient expression (Fig. 8e). Transient overexpression of MKK7 resulted in macroscopic cell death in $N$. benthamiana tissues (Fig. 8c), possibly as a result of immune activation, as previously suggested by the failure to generate Arabidopsis transgenic plants expressing this kinase from a $35 \mathrm{~S}$ promoter (Dai et al., 2006; X. Zhang et al., 2007). Interestingly, neither the bona fide mutant protein $\mathrm{MKK} 7^{\mathrm{K} 74 \mathrm{R}}$ nor MKK7 ${ }^{\mathrm{K} 167 \mathrm{R}}$ expression elicited macroscopic cell death (Fig. 8c), nor ion leakage associated with the onset of cell death in N. benthamiana tissues (Fig. 8d). Furthermore, we performed DEX-inducible expression in Arabidopsis transgenic plants of MKK7-3XFLAG or MKK $7^{\mathrm{K} 167 \mathrm{R}}-3 \mathrm{XFLAG}$, followed by Pto DC3000 inoculation, to confirm K167 requirement for the MKK7-dependent basal defence response shown in Fig. 3(a). We found that MKK $7^{\mathrm{K} 167 \mathrm{R}}-3 \mathrm{XFLAG}$ overexpressing plants did not display the enhanced resistance to Pto DC3000 shown by plants overexpressing MKK7-3XFLAG (Fig. 8f). These results indicated that the K167 residue, targeted for acetylation by HopZ1a, is essential for MKK7 activity in planta.

\section{Discussion}

In this work we identified and characterised the interaction between the P. syringae T3E HopZ1a and Arabidopsis MKK7, a positive regulator of plant defence. We show that this interaction results in acetylation of $\mathrm{MKK} 7$, possibly in a lysine essential for kinase activity. We demonstrated that bacteria-delivered HopZ1a suppresses MKK7-dependent defence responses, therefore providing a molecular mechanism for HopZ1a simultaneous suppression of PTI, ETI and SAR. As overexpressing effectors from transgenic plants can be prone to artefacts, we used T3SSdependent translocation from inoculated bacteria, therefore analysing effector function at a physiological concentration.

While we have shown that HopZ1a interference with MKK7 can explain HopZ1a-dependent defence suppression at all levels (PTI, ETI and SAR), our results do not rule out additional HopZ1a interactions with other Arabidopsis MKKs, considering the overall conservation among this class of kinases (Fig. S7). This is the case with other T3Es, such as HopF2 that interacts with several Arabidopsis MKKs (Wang et al., 2010), or YopJ that acetylates several mammalian MKKs (Mukherjee et al., 2006) (Paquette et al., 2012). However, confocal imaging showed HopZ1a co-localisation with MKK7 in the plasma membrane or its immediate vicinity, while the redundant pair MKK4/5, which is also a positive regulator of defence, was detected only in the nucleus (Fig. S1). This implies a certain degree of specificity in HopZ1a interaction with MKKs, if only as a consequence of their respective subcellular locations. While HopZ1a interference with other MKKs that are positive regulators of defence might contribute to HopZ1a-associated phenotypes, our results suggested that HopZ1a interaction with MKKs within the host cell is not all inclusive. Furthermore, only MKK7 has been proven essential for SAR activation to date (X. Zhang et al., 2007), 
(a)

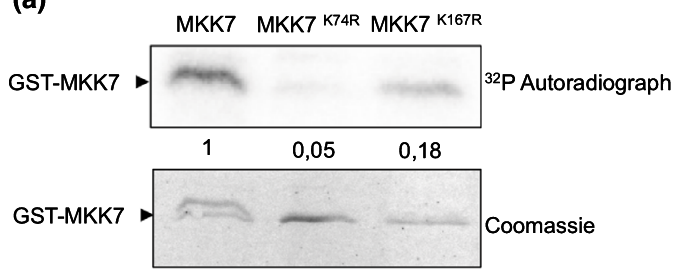

(b)

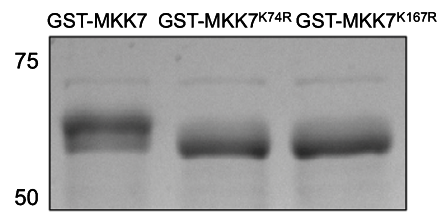

(c)

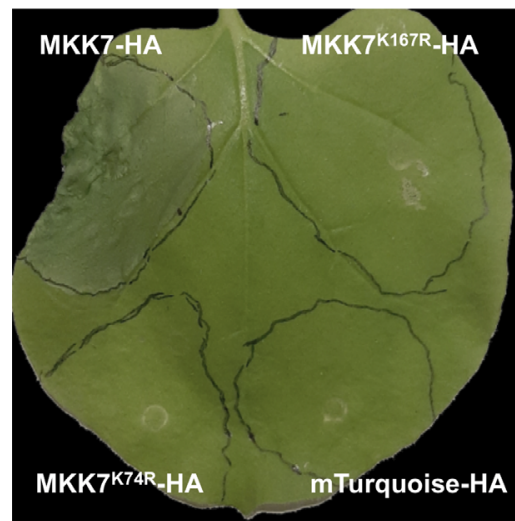

(e)

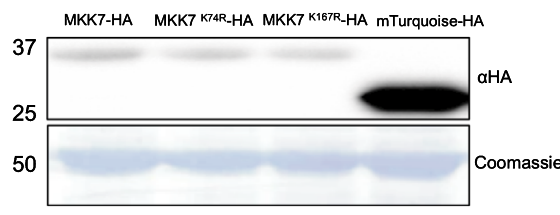

(d)

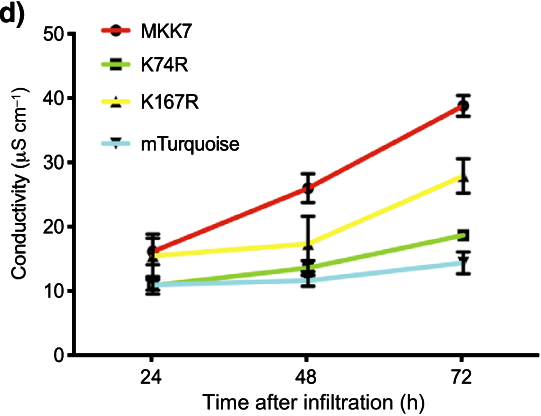

P. syringae DC3000 growth

(f)

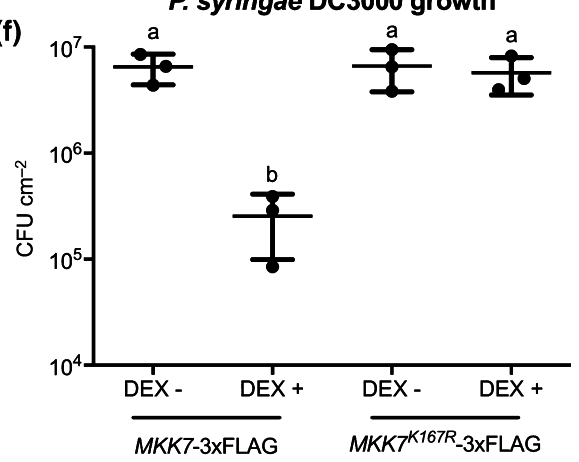

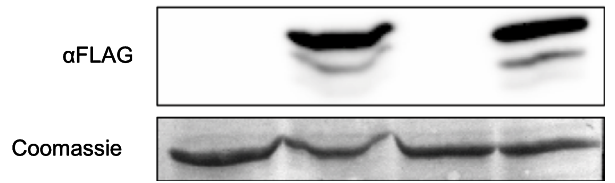

Fig. 8 K167 is required for full MKK7 activity in vitro and in planta. (a) In vitro kinase assay. Here $1 \mu \mathrm{g}$ of GST-MKK7, GST-MKK7 ${ }^{\text {K74R }}$ or GST-MKK7 ${ }^{\text {K167R }}$ was incubated in kinase buffer containing ${ }^{32} \mathrm{P}-\gamma$-ATP. Samples were separated by SDS-PAGE and proteins were transferred to a PVDF membrane. The membrane was exposed to an imaging plate for $1 \mathrm{~d}$ and autophosphorylation was detected by autoradiography. Coomassie staining is shown as the loading control. (b) In total, $5 \mu \mathrm{g}$ of GST-MKK7, GST-MKK $7^{\mathrm{K} 74 \mathrm{R}}$ or GST-MKK $7^{\mathrm{K} 167 \mathrm{R}}$ were separated by SDS-PAGE. SDS-PAGE were stained with Coomassie staining. (c) Cell death induced by MKK7. Transient expression in Nicotiana benthamiana leaves inoculated with Agrobacterium tumefaciens

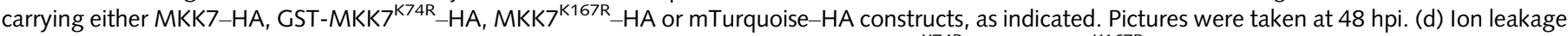
assay in $N$. benthamiana leaves inoculated with $A$. tumefaciens carrying MKK7-HA, MKK $7^{\text {K74R }}-\mathrm{HA}$, MKK $7^{\mathrm{K} 167 \mathrm{R}}$-HA or mTurquoise-HA constructs. Conductivity was measured at the indicated time points. Graph indicates mean values $(n=3)$ and error bars indicate SE. Experiments were repeated three times with similar results. (e) Protein accumulation in N. benthamiana leaves was detected $24 \mathrm{hpi}$ by Western blot analysis. Coomassie staining is shown as

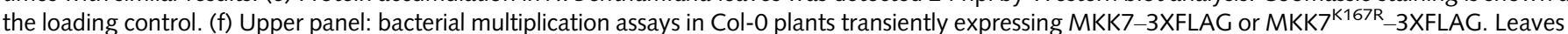
were syringe infiltrated with a $5 \times 10^{4} \mathrm{CFU} \mathrm{ml}{ }^{-1}$ suspension of Pto DC3000. Plants were treated with either DEX (DEX+) or Mock solution (DEX-) $2 \mathrm{~h}$ before bacterial inoculation. The graphs show bacterial titres at $4 \mathrm{~d}$ post inoculation (dpi). Lines represent mean values and error bars represent $\mathrm{SE}(n=5)$. Individual values are also shown. Statistical differences were determined using one-way ANOVA $(n=0.05)$ with Tukey's multiple comparisons test and different letters indicate statistical significance. Lower panel: MKK7 and MKK ${ }^{\mathrm{K} 167 \mathrm{R}}$ expression levels in the corresponding samples were detected $48 \mathrm{~h}$ after treatment by Western blot analysis using an anti-3XFLAG antibody on total protein extracts from leaf discs. Coomassie staining is shown as the loading control.

which implies a distinctive role for this novel target in HopZ1a suppression of systemic defence (Fig. 6).

Our results indicated that HopZ1a acetylates MKK7 both in vitro and in planta, preferentially in a conserved, essential lysine located in the catalytic loop, probably involved in the coordination of ATP binding (Figs 7, S6, S7). HopZ1a autoacetylates in lysine K289 (Lee et al., 2012; Ma et al., 2015; Rufián et al., 2015), while several effectors of the HopZ1 superfamily, such as 
YopJ, AvrA or VopA, acetylate lysine residues on their target MKKs, resulting in inhibition of kinase activity and suppression of immune responses (Mukherjee et al., 2006; Trosky et al., 2007; Jones et al., 2008; Paquette et al., 2012). We propose that HopZ1a interferes with MKK7 in a manner analogous to that of VopA on MKK6 (Trosky et al., 2007).

HopZ1a might also modify additional MKK7 residues to interfere with kinase function. HopZ1a acetylates serine and threonine residues of PBL1 (Bastedo et al., 2019) and ZED1 (Lewis et al., 2013), and autoacetylates in two essential serine residues (Ma et al., 2015). Furthermore, YopJ, AvrA and VopA acetylate key serine and threonine residues in the activation loop of their target kinases (Mittal et al., 2006; Mukherjee et al., 2006; Trosky et al., 2007; Jones et al., 2008; Meinzer et al., 2012; Paquette et al., 2012; Ma \& Ma, 2016). As we have followed a direct approach, we cannot rule out additional HopZ1a acetylation of serine and/or threonine residues on MKK7. However, Popescu et al. (2009) showed that wild-type MKK7 was more active than the constitutively active mutant version, when essential serine and threonine residues in the activation loop were replaced with glutamic acid, suggesting that MKK7 could be regulated through phosphorylation of residues located outside the activation loop.

Current knowledge indicated that a single effector can have multiple host target proteins. While here we report HopZ1a interference with plant defence via MKK7, HopZ1a-associated suppression phenotypes are likely to arise from its combined interference of several participants in local and systemic defences. HopZ1a interacts with several plant kinases associated with immune signalling such as PBS1-like (PBL) (Bastedo et al., 2019), SZE1 or SZE2 (Liu et al., 2019). The structural conservation amongst kinases probably facilitates a certain laxity in target selection. Simultaneous action on several kinase-regulated links of the plant signalling process probably results in a more substantial interference in susceptible plants. Interestingly, the HopZ1a homologue HopZ3 also interacts with some plant RLCKs and also with a MAP kinase, acetylating some of these targets to interfere with plant defence (Lee et al., 2015).

The proposed scenario does not preclude a role for additional targets, other than kinases, previously described for HopZ1a (Lee et al., 2012; Jiang et al., 2013; Albers et al., 2019). Some targets, such as remorin (Albers et al., 2019), are directly associated with the aforementioned kinases, as co-participants in defence signalling. In other instances, the virulence effect described for HopZ1a interference with a particular interactor might be indirect. This might be the case for the destruction of the plant microtubule network associated with HopZ1a interaction with tubulin (Lee et al., 2012). The authors discussed that microtubule destruction might be an indirect effect of HopZ1a acting on an unidentified protein, suggesting a MAPK as a likely possibility. HopZ1a interacts with microtubule-associated kinesins (Lee et al., 2019), which are in close association with the MAPK cascade (reviewed by Liang \& Yang, 2019). MKK7 interacts with MPK6, which localises to microtubules (Muller et al., 2010; Shen et al., 2019), and several microtubule-associated proteins are substrates of the MKK7/MPK3-6 module in Arabidopsis (Strack et al., 2013; Huck et al., 2017).
HopZ1a associates through myristoylation to the plasma membrane (Lewis et al., 2008), where many of its interactors are located (Wilton et al., 2010; Zhou et al., 2014; Albers et al., 2019; Bastedo et al., 2019; Liu et al., 2019). In the conditions assayed, AtMKK7 is preferentially located in the plasma membrane, as shown by its co-localisation with HopZ1a and with the membrane-associated calcineurin B-like protein used as a control (Fig. S1). Furthermore, AtMKK7 is recruited to the plasma membrane under stress conditions, after binding to phosphatidic acid (PA) (Shen et al., 2019), a lipid secondary messenger involved in early defence signalling that targets proteins to the cell membrane (reviewed by Zhao, 2015; Yao \& Xue, 2018). Therefore, HopZ1a could come in close contact with MKK7 after the latter is relocated to the plasma membrane by PA accumulation, as part of the early plant defence response to pathogen attack. This will be coherent with the HopZ1a ability to suppress AvrRps4, AvrRpm1 and AvrRpt2-triggered ETI (Macho et al., 2010), and also with AtMKK7 contribution to RPS2-mediated immunity (Fig. 4). It is tempting to speculate that HopZ1a could be part of a membrane-associated protein complex involving multiple host targets plus those partner effectors shielded by HopZ1a from triggering ETI, as has been shown for HopZ3 (Lee et al., 2015).

HopZ1a interference with AtMKK7 resulting in the suppression of SAR is one of its most distinctive phenotypes. Broadly, SAR signals via two parallel branches, one regulated by SA and the second by azelaic acid (AzA), G3P, nitric oxide, and ROS (Klessig et al., 2018; Shine et al., 2019). Feeding into both branches is pipecolic acid (Pip), a metabolite indispensable for SAR that is synthesised from lysine in a process dependent on the aminotransferase ALD1 (Navarova et al., 2012; Bernsdorff et al., 2016). Indeed, our results indicated that MKK7 expression resulted in increased ALD1 mRNA levels (Fig. 6c). MKK7 downstream targets can provide an insight into the molecular events following HopZ1a interference with MKK7 with regards to systemic immunity suppression. Activation of the MKK7/ MPK10 module leads to phosphorylation of DNA-binding factor TGA1 (Popescu et al., 2009), which positively regulates basal resistance and is required for SAR, as it activates gene expression leading to increased SA and Pip biosynthesis (Navarova et al., 2012; Bernsdorff et al., 2016; Sun et al., 2018). Additionally, the MKK7/MPK3-6 module has been associated with plant defence (Yoo et al., 2008; Jia et al., 2016; Huck et al., 2017; Shen et al., 2019). Interestingly, MPK3 interacts with AZA INDUCED 1 (AZI1), a lipid-transfer protein that mediates AzA uptake and mobilisation (Jung et al., 2009; Pitzschke et al., 2014; Cecchini et al., 2015). In summary, the MKK7/MPK10 and MKK7/MPK3-6 modules might contribute to MKK7-dependent SAR activation via both SAR signalling branches, by promoting $\mathrm{SA}$ and pipecolic acid biosynthesis and facilitating AzA-dependent signalling.

HopZ1a suppression of SAR could also derive from indirect changes of hormone-dependent immune signalling. MKK7 establishes a crosstalk point between auxin signalling and plant responses to biotic and abiotic stresses (Zhang et al., 2008; Jia et al., 2016; Dory et al., 2018). Auxin signalling participates in 
the establishment and maintenance of SAR triggered by virulent P. syringae (Bennett et al., 1996; Kepinski \& Leyser, 2005; Dharmasiri et al., 2006; Truman et al., 2010). Jasmonates also have been proposed to participate in SAR signalling (Truman et al., 2007; Chaturvedi et al., 2008). HopZ1a interacts with JAZ transcriptional repressors, inducing its degradation and therefore promoting JA-responsive gene expression (Jiang et al., 2013), raising the possibility that interference with JA signalling may contribute to HopZ1-mediated SAR suppression. Further studies will be necessary to understand the integrated impact of HopZ1a virulence activities in plant hormone and defence signalling.

\section{Acknowledgements}

We wish to thank Zhonglin Mou (University of Florida) for his kind gift of Arabidopsis $M K K 7$-DEX and as $M K K 7$ plants, and A. Esteban for help with the zar1-1 crossings. We also wish to thank Vitor Amorim-Silva for technical advice, and Dr Lucía, Dr Castillo, B. Sabarit and P. García Vallejo for technical help.

This work was supported by Project Grants RTI2018095069-B-I00 from the Spanish Ministerio de Ciencia, Innovación y Universidades and BIO2015-64391-R from the Spanish Ministerio de Economía y Competitividad, both awarded to CRB and JR-A. JRB was partially funded by a Project Grant (UMA18-FEDERJA-070) from the Programa Operativo Fondos Europeos de Desarrollo Regional (FEDER) Andalucía, awarded to JR-A. DLM was partially funded by a FPU Grant (Predoctoral Fellowship from the Spanish Ministerio de Educación, Cultura y Deporte; FPU14/04233). The work was co-funded by FEDER. This work was also funded by the Strategic Priority Research Program of the Chinese Academy of Sciences (grant XDB27040204 to APM), the National Natural Science Foundation of China (grant 31571973 to APM), the Financial Grant from the China Postdoctoral Science Foundation (grant 2017M621549 to JS-R) and the President's International Fellowship Initiative (PIFI) (fellowships 2018PB0057 and 2020PB0088 to JS-R).

\section{Author contribution}

JSR, JR-A, JRB, CB and AM contributed to the overall conception and design of the methodology and experimental work. The acquisition of data and its primary analysis has been the responsibility of JSR, JR-B and DL-M, while all authors contributed to the final interpretation of the data. The paper has been drafted by the combined efforts of JR, CB and JR-A, with additional contribution to the final version by AM, after critical revision. JSR and JR-B contributed equally to this work.

\section{ORCID}

Carmen R. Beuzón (iD https://orcid.org/0000-0002-6888-3845 Diego López-Márquez (iD https://orcid.org/0000-0002-59234392

Alberto P. Macho (iD https://orcid.org/0000-0001-9935-8026 Javier Rueda-Blanco (D) https://orcid.org/0000-0001-7027-2384
José S. Rufián (ID https://orcid.org/0000-0002-3871-3706

Javier Ruiz-Albert (D) https://orcid.org/0000-0003-4110-1206

\section{References}

Adam L, Somerville SC. 1996. Genetic characterization of five powdery mildew disease resistance loci in Arabidopsis thaliana. The Plant Journal 9: 341-356.

Albers P, Ustun S, Witzel K, Kraner M, Bornke F. 2019. A Remorin from Nicotiana benthamiana interacts with the Pseudomonas type-III effector protein HopZ1a and is phosphorylated by the immune-related kinase PBS1. Molecular Plant-Microbe Interactions 32: 1229-1242.

Asai T, Tena G, Plotnikova J, Willmann MR, Chiu WL, Gomez-Gomez L, Boller T, Ausubel FM, Sheen J. 2002. MAP kinase signalling cascade in Arabidopsis innate immunity. Nature 415: 977-983.

Axtell MJ, Staskawicz BJ. 2003. Initiation of RPS2-specified disease resistance in Arabidopsis is coupled to the AvrRpt2-directed elimination of RIN4. Cell 112: 369-377.

Bastedo DP, Khan M, Martel A, Seto D, Kireeva I, Zhang J, Masud W, Millar D, Lee JY, Lee A-Y et al. 2019. Perturbations of the ZED1 pseudokinase activate plant immunity. PLoS Pathogens 15: e1007900.

Baudin M, Hassan JA, Schreiber KJ, Lewis JD. 2017. Analysis of the ZAR1 immune complex reveals determinants for immunity and molecular interactions. Plant physiology 174: 2038-2053.

Bennett M, Gallagher M, Fagg J, Bestwick C, Paul T, Beale M, Mansfield J. 1996. The hypersensitive reaction, membrane damage and accumulation of autofluorescent phenolics in lettuce cells challenged by Bremia lactucae. The Plant Journal 9: 851-865.

Bernsdorff F, Doring AC, Gruner K, Schuck S, Brautigam A, Zeier J. 2016. Pipecolic acid orchestrates plant systemic acquired resistance and defense priming via salicylic acid-dependent and -independent pathways. The Plant Cell 28: 102-129.

Boller T, Felix G. 2009. A renaissance of elicitors: perception of microbeassociated molecular patterns and danger signals by pattern-recognition receptors. Annual Review of Plant Biology 60: 379-406.

Cecchini NM, Steffes K, Schlappi MR, Gifford AN, Greenberg JT. 2015. Arabidopsis AZI1 family proteins mediate signal mobilization for systemic defence priming. Nature Communications 6: 7658 .

Chaturvedi R, Krothapalli K, Makandar R, Nandi A, Sparks AA, Roth MR, Welti R, Shah J. 2008. Plastid omega3-fatty acid desaturase-dependent accumulation of a systemic acquired resistance inducing activity in petiole exudates of Arabidopsis thaliana is independent of jasmonic acid. The Plant Journal 54: 106-117.

Chiang Y-H, Coaker G. 2015. Effector triggered immunity: NLR immune perception and downstream defense responses. The Arabidopsis book 13: e0183.

Clough SJ, Bent AF. 1998. Floral dip: a simplified method for Agrobacteriummediated transformation of Arabidopsis thaliana. The Plant Journal 16: 735743.

Cuppels DA. 1986. Generation and characterization of $\operatorname{Tn} 5$ insertion mutations in Pseudomonas syringae pv. tomato. Applied and Environment Microbiology 51: 323-327.

Dai Y, Wang H, Li B, Huang J, Liu X, Zhou Y, Mou Z, Li J. 2006. Increased expression of MAP KINASE KINASE7 causes deficiency in polar auxin transport and leads to plant architectural abnormality in Arabidopsis. The Plant Cell 18: 308-320.

Deblaere R, Bytebier B, De Greve H, Deboeck F, Schell J, Van Montagu M, Leemans J. 1985. Efficient octopine Ti plasmid-derived vectors for Agrobacterium-mediated gene transfer to plants. Nucleic Acids Research 13: 4777-4788.

Dharmasiri S, Swarup R, Mockaitis K, Dharmasiri N, Singh SK, Kowalchyk M, Marchant A, Mills S, Sandberg G, Bennett MJ et al. 2006. AXR4 is required for localization of the auxin influx facilitator AUX1. Science 312: $1218-1220$.

Doczi R, Brader G, Pettko-Szandtner A, Rajh I, Djamei A, Pitzschke A, Teige M, Hirt H. 2007. The Arabidopsis mitogen-activated protein kinase kinase MKK3 is upstream of group $\mathrm{C}$ mitogen-activated protein kinases and participates in pathogen signaling. The Plant Cell 19: 3266-3279. 
Dory M, Hatzimasoura E, Kállai BM, Nagy SK, Jäger K, Darula Z, Nádai TV, Mészáros T, López-Juez E, Barnabás B et al. 2018. Coevolving MAPK and PID phosphosites indicate an ancient environmental control of PIN auxin transporters in land plants. FEBS Letters 592: 89-102.

Feng F, Yang F, Rong W, Wu X, Zhang J, Chen S, He C, Zhou JM. 2012. A Xanthomonas uridine $5^{\prime}$-monophosphate transferase inhibits plant immune kinases. Nature 485: 114-118.

Govantes F, Molina-Lopez JA, Santero E. 1996. Mechanism of coordinated synthesis of the antagonistic regulatory proteins NifL and NifA of Klebsiella pneumoniae. Journal of Bacteriology 178: 6817-6823.

Hanahan D. 1983. Studies of transformation of Escherichia coli with plasmids. Journal of Molecular Biology 166: 557-580.

Huang HC, Schuurink R, Denny TP, Atkinson MM, Baker CJ, Yucel I, Hutcheson SW, Collmer A. 1988. Molecular cloning of a Pseudomonas syringae pv. syringae gene cluster that enables Pseudomonas fluorescens to elicit the hypersensitive response in tobacco plants. Journal of Bacteriology 170 : 4748-4756.

Huck NV, Leissing F, Majovsky P, Buntru M, Aretz C, Flecken M, Müller JPJ, Vogel S, Schillberg S, Hoehenwarter W et al. 2017. Combined ${ }^{15} \mathrm{~N}$-Labeling and TandemMOAC quantifies phosphorylation of MAP kinase substrates downstream of MKK7 in Arabidopsis. Frontiers in Plant Science 8: 2050.

Jamir Y, Guo M, Oh HS, Petnicki-Ocwieja T, Chen S, Tang X, Dickman MB, Collmer A, Alfano JR. 2004. Identification of Pseudomonas syringae type III effectors that can suppress programmed cell death in plants and yeast. The Plant Journal 37: 554-565.

Jia W, Li B, Li S, Liang Y, Wu X, Ma M, Wang J, Gao J, Cai Y, Zhang Y et al. 2016. Mitogen-activated protein kinase cascade MKK7-MPK6 plays important roles in plant development and regulates shoot branching by phosphorylating PIN1 in Arabidopsis. PLoS Biology 14: e1002550.

Jiang S, Yao J, Ma KW, Zhou H, Song J, He SY, Ma W. 2013. Bacterial effector activates jasmonate signaling by directly targeting JAZ transcriptional repressors. PLoS Pathogens 9: e1003715.

Jones JD, Dangl JL. 2006. The plant immune system. Nature 444: 323-329.

Jones RM, Wu H, Wentworth C, Luo L, Collier-Hyams L, Neish AS. 2008. Salmonella AvrA coordinates suppression of host immune and apoptotic defenses via JNK pathway blockade. Cell Host \& Microbe 3: 233-244.

Jung HW, Tschaplinski TJ, Wang L, Glazebrook J, Greenberg JT. 2009. Priming in systemic plant immunity. Science 324: 89-91.

Kepinski S, Leyser O. 2005. The Arabidopsis F-box protein TIR1 is an auxin receptor. Nature 435: 446-451.

Klessig DF, Choi HW, Dempsey DA. 2018. Systemic acquired resistance and salicylic acid: past, present, and future. Molecular Plant-Microbe Interactions 31: 871-888.

Lee AH, Bastedo DP, Youn JY, Lo T, Middleton MA, Kireeva I, Lee JY, Sharifpoor S, Baryshnikova A, Zhang J et al. 2019. Identifying Pseudomonas syringae type III secreted effector function via a yeast genomic screen. $G 3$ (Bethesda) 9: 535-547.

Lee A-Y, Hurley B, Felsensteiner C, Yea C, Ckurshumova W, Bartetzko V, Wang PW, Quach V, Lewis JD, Liu YC et al. 2012. A bacterial acetyltransferase destroys plant microtubule networks and blocks secretion. PLoS Pathogens 8: e1002523.

Lee J, Manning AJ, Wolfgeher D, Jelenska J, Cavanaugh KA, Xu H, Fernandez SM, Michelmore RW, Kron SJ, Greenberg JT. 2015. Acetylation of an NBLRR plant immune-effector complex suppresses immunity. Cell Reports 13: $1670-1682$.

Lewis JD, Abada W, Ma W, Guttman DS, Desveaux D. 2008. The HopZ family of Pseudomonas syringae type III effectors require myristoylation for virulence and avirulence functions in Arabidopsis thaliana. Journal of Bacteriology 190: 2880-2891.

Lewis Jd, Lee A h-y, Hassan Ja, Wan J, Hurley B, Jhingree Jr, Wang Pw, Lo T, Youn J-y, Guttman Ds et al. 2013. The Arabidopsis ZED1 pseudokinase is required for ZAR1-mediated immunity induced by the Pseudomonas syringae type III effector HopZ1a. Proceedings of the National Academy of Sciences, USA 110: $18722-18727$.
Lewis JD, Wilton M, Mott GA, Lu W, Hassan JA, Guttman DS, Desveaux D. 2014. Immunomodulation by the Pseudomonas syringae HopZ type III effector family in Arabidopsis. PLOS ONE 9: e116152.

Lewis JD, Wu R, Guttman DS, Desveaux D. 2010. Allele-specific virulence attenuation of the Pseudomonas syringae HopZ1a type III effector via the Arabidopsis ZAR1 resistance protein. PLoS Genetics 6: e1000894.

Li W, Yadeta KA, Elmore JM, Coaker G. 2013. The Pseudomonas syringae effector HopQ1 promotes bacterial virulence and interacts with tomato 14-3-3 proteins in a phosphorylation-dependent manner. Plant Physiology 161: 20622074.

Liang YJ, Yang WX. 2019. Kinesins in MAPK cascade: How kinesin motors are involved in the MAPK pathway? Gene 684: 1-9.

Liu C, Cui D, Zhao J, Liu Na, Wang Bo, Liu J, Xu E, Hu Z, Ren D, Tang D et al. 2019. Two Arabidopsis receptor-like cytoplasmic kinases SZE1 and SZE2 associate with the ZAR1-ZED1 complex and are required for effector-triggered immunity. Molecular Plant 12: 967-983.

Ma KW, Jiang S, Hawara E, Lee D, Pan S, Coaker G, Song J, Ma W. 2015. Two serine residues in Pseudomonas syringae effector HopZ1a are required for acetyltransferase activity and association with the host co-factor. New Phytologist 208: 1157-1168.

Ma KW, Ma W. 2016. YopJ family effectors promote bacterial infection through a unique acetyltransferase activity. Microbiology and Molecular Biology Reviews: MMBR 80: 1011-1027.

Ma W, Dong FF, Stavrinides J, Guttman DS. 2006. Type III effector diversification via both pathoadaptation and horizontal transfer in response to a coevolutionary arms race. PLoS Genetics 2: e209.

Macho AP, Guevara CM, Tornero P, Ruiz-Albert J, Beuzon CR. 2010. The Pseudomonas syringae effector protein HopZ1a suppresses effector-triggered immunity. New Phytologist 187: 1018-1033.

Macho AP, Rufian JS, Ruiz-Albert J, Beuzon CR. 2016. Competitive Index: mixed infection-based virulence assays for genetic analysis in Pseudomonas syringae-plant interactions. Methods in Molecular Biology 1363: 209-217.

Macho AP, Ruiz-Albert J, Tornero P, Beuzón CR. 2009. Identification of new type III effectors and analysis of the plant response by competitive index. Molecular Plant Pathology 10: 69-80.

Macho AP, Zumaquero A, Ortiz-Martín I, Beuzón CR. 2007. Competitive index in mixed infections: a sensitive and accurate assay for the genetic analysis of Pseudomonas syringae-plant interactions. Molecular Plant Pathology 8: 437450.

Mackey D, Belkhadir Y, Alonso JM, Ecker JR, Dangl JL. 2003. Arabidopsis RIN4 is a target of the type III virulence effector AvrRpt2 and modulates RPS2-mediated resistance. Cell 112: 379-389.

Meinzer U, Barreau F, Esmiol-Welterlin S, Jung C, Villard C, Léger T, BenMkaddem S, Berrebi D, Dussaillant M, Alnabhani Z et al. 2012. Yersinia pseudotuberculosis effector YopJ subverts the Nod2/RICK/TAK1 pathway and activates caspase-1 to induce intestinal barrier dysfunction. Cell Host \& Microbe 11: 337-351.

Meng X, Zhang S. 2013. MAPK cascades in plant disease resistance signaling. Annual Review of Phytopathology 51: 245-266.

Mittal R, Peak-Chew SY, McMahon HT. 2006. Acetylation of MEK2 and I kappa B kinase (IKK) activation loop residues by YopJ inhibits signaling. Proceedings of the National Academy of Sciences, USA 103: 18574-18579.

Mukherjee S, Keitany G, Li Y, Wang Y, Ball HL, Goldsmith EJ, Orth K. 2006. Yersinia YopJ acetylates and inhibits kinase activation by blocking phosphorylation. Science 312: 1211-1214.

Muller J, Beck M, Mettbach U, Komis G, Hause G, Menzel D, Samaj J. 2010 Arabidopsis MPK6 is involved in cell division plane control during early root development, and localizes to the pre-prophase band, phragmoplast, transGolgi network and plasma membrane. The Plant Journal 61: 234-248.

Nakagawa T, Suzuki T, Murata S, Nakamura S, Hino T, Maeo K, Tabata R, Kawai T, Tanaka K, Niwa $\mathrm{Y}$ et al. 2007. Improved Gateway binary vectors: high-performance vectors for creation of fusion constructs in transgenic analysis of plants. Bioscience, Biotechnology and Biochemistry 71: 2095-2100.

Navarova H, Bernsdorff F, Doring AC, Zeier J. 2012. Pipecolic acid, an endogenous mediator of defense amplification and priming, is a critical regulator of inducible plant immunity. The Plant Cell 24: 5123-5141. 
Paquette N, Conlon J, Sweet C, Rus F, Wilson L, Pereira A, Rosadini CV, Goutagny N, Weber AN, Lane WS et al. 2012. Serine/threonine acetylation of TGFbeta-activated kinase (TAK1) by Yersinia pestis YopJ inhibits innate immune signaling. Proceedings of the National Academy of Sciences, USA 109: $12710-12715$.

Pitzschke A, Datta S, Persak H. 2014. Salt stress in Arabidopsis: lipid transfer protein AZI1 and its control by mitogen-activated protein kinase MPK3. Molecular Plant 7: 722-738.

Pitzschke A, Schikora A, Hirt H. 2009. MAPK cascade signalling networks in plant defence. Current Opinion in Plant Biology 12: 421-426.

Popescu SC, Popescu GV, Bachan S, Zhang Z, Gerstein M, Snyder M, DineshKumar SP. 2009. MAPK target networks in Arabidopsis thaliana revealed using functional protein microarrays. Genes \& Development 23: 80-92.

Rosas-Diaz T, Zhang D, Fan P, Wang L, Ding X, Jiang Y, Jimenez-Gongora T, Medina-Puche L, Zhao X, Feng $Z$ et al. 2018. A virus-targeted plant receptorlike kinase promotes cell-to-cell spread of RNAi. Proceedings of the National Academy of Sciences, USA 115: 1388-1393.

Rufián JS, Lopez-Marquez D, Lopez-Pagan N, Grant M, Ruiz-Albert J, Beuzon CR. 2018a. Generating chromosome-located transcriptional fusions to fluorescent proteins for single-cell gene expression analysis in Pseudomonas syringae. Methods in Molecular Biology 1734: 183-199.

Rufián JS, Lucía A, Macho AP, Orozco-Navarrete B, Arroyo-Mateos MA, Bejarano ER, Beuzón CR, Ruiz-Albert J. 2015. Auto-acetylation on K289 is not essential for HopZ1a-mediated plant defense suppression. Frontiers in Microbiology 6: 684 .

Rufián JS, Lucia A, Rueda-Blanco J, Zumaquero A, Guevara CM, Ortiz-Martin I, Ruiz-Aldea G, Macho AP, Beuzon CR, Ruiz-Albert J. 2018b. Suppression of HopZ effector-triggered plant immunity in a natural pathosystem. Frontiers in plant science 9: 977.

Rufián JS, Rueda-Blanco J, Beuzon CR, Ruiz-Albert J. 2019. Protocol: an improved method to quantify activation of systemic acquired resistance (SAR). Plant Methods 15: 16

Sang Y, Macho AP. 2017. Analysis of PAMP-triggered ROS burst in plant immunity. Methods in Molecular Biology 1578: 143-153.

Shen L, Zhuang B, Wu Q, Zhang H, Nie J, Jing W, Yang L, Zhang W. 2019. Phosphatidic acid promotes the activation and plasma membrane localization of MKK7 and MKK9 in response to salt stress. Plant Science 287: 110190.

Shine MB, Xiao X, Kachroo P, Kachroo A. 2019. Signaling mechanisms underlying systemic acquired resistance to microbial pathogens. Plant Science 279: 81-86.

Song JT, Lu H, McDowell JM, Greenberg JT. 2004. A key role for ALD1 in activation of local and systemic defenses in Arabidopsis. The Plant Journal 40: 200-212.

Spoel SH, Dong X. 2012. How do plants achieve immunity? Defence without specialized immune cells. Nature Reviews Immunology 12: 89-100.

Strack S, Wilson TJ, Cribbs JT. 2013. Cyclin-dependent kinases regulate splicespecific targeting of dynamin-related protein 1 to microtubules. Journal of Cell Biology 201: 1037-1051.

Sun T, Busta L, Zhang Q, Ding P, Jetter R, Zhang Y. 2018. TGACGBINDING FACTOR 1 (TGA1) and TGA4 regulate salicylic acid and pipecolic acid biosynthesis by modulating the expression of SYSTEMIC ACQUIRED RESISTANCE DEFICIENT 1 (SARD1) and CALMODULIN-BINDING PROTEIN 60g (CBP60g). New Phytologist 217: 344-354.

Trosky JE, Li Y, Mukherjee S, Keitany G, Ball H, Orth K. 2007. VopA inhibits ATP binding by acetylating the catalytic loop of MAPK kinases. Journal of Biological Chemistry 282: 34299-34305.

Trosky JE, Mukherjee S, Burdette DL, Roberts M, McCarter L, Siegel RM, Orth K. 2004. Inhibition of MAPK signaling pathways by VopA from Vibrio parahaemolyticus. Journal of Biological Chemistry 279: 51953-51957.

Truman W, Bennett MH, Kubigsteltig I, Turnbull C, Grant M. 2007. Arabidopsis systemic immunity uses conserved defense signaling pathways and is mediated by jasmonates. Proceedings of the National Academy of Sciences, USA 104: 1075-1080.

Truman WM, Bennett MH, Turnbull CG, Grant MR. 2010. Arabidopsis auxin mutants are compromised in systemic acquired resistance and exhibit aberrant accumulation of various indolic compounds. Plant physiology 152: $1562-1573$.

Wang D, Weaver ND, Kesarwani M, Dong X. 2005. Induction of protein secretory pathway is required for systemic acquired resistance. Science 308: 1036-1040.

Wang Y, Li J, Hou S, Wang X, Li Y, Ren D, Chen S, Tang X, Zhou JM. 2010. A Pseudomonas syringae ADP-ribosyltransferase inhibits Arabidopsis mitogenactivated protein kinase kinases. The Plant Cell 22: 2033-2044.

Wang Y, Li Y, Rosas-Diaz T, Caceres-Moreno C, Lozano-Duran R, Macho AP. 2019. The IMMUNE-ASSOCIATED NUCLEOTIDE-BINDING 9 protein is a regulator of basal immunity in Arabidopsis thaliana. Molecular Plant Microbe Interactions 32: 65-75.

Washington EJ, Mukhtar MS, Finkel OM, Wan L, Banfield MJ, Kieber JJ, Dangl JL. 2016. Pseudomonas syringae type III effector HopAF1 suppresses plant immunity by targeting methionine recycling to block ethylene induction. Proceedings of the National Academy of Sciences, USA 113: E3577-3586.

Wilton M, Subramaniam R, Elmore J, Felsensteiner C, Coaker G, Desveaux D. 2010. The type III effector HopF2 Pto targets Arabidopsis RIN4 protein to promote Pseudomonas syringae virulence. Proceedings of the National Academy of Sciences, USA 107: 2349-2354.

Yadeta KA, Elmore JM, Creer AY, Feng B, Franco JY, Rufian JS, He P, Phinney B, Coaker G. 2017. A cysteine-rich protein kinase associates with a membrane immune complex and the cysteine residues are required for cell death. Plant Physiology 173: 771-787.

Yao HY, Xue HW. 2018. Phosphatidic acid plays key roles regulating plant development and stress responses. Journal of Integrative Plant Biology 60: 851863.

Yoo SD, Cho YH, Tena G, Xiong Y, Sheen J. 2008. Dual control of nuclear EIN3 by bifurcate MAPK cascades in C2H4 signalling. Nature 451: 789-795.

Yu G, Xian L, Xue H, Yu W, Rufian JS, Sang Y, Morcillo RJL, Wang Y, Macho AP. 2020. A bacterial effector protein prevents MAPK-mediated phosphorylation of SGT1 to suppress plant immunity. PLoS Pathogens 16: e1008933.

Zhang J, Shao F, Li Y, Cui H, Chen L, Li H, Zou Y, Long C, Lan L, Chai J et al. 2007. A Pseudomonas syringae effector inactivates MAPKs to suppress PAMP-induced immunity in plants. Cell Host and Microbe 1: 175-185.

Zhang X, Dai Y, Xiong Y, DeFraia C, Li J, Dong X, Mou Z. 2007. Overexpression of Arabidopsis MAP kinase kinase 7 leads to activation of plant basal and systemic acquired resistance. The Plant Journal 52: 1066-1079.

Zhang X, Xiong Y, Defraia C, Schmelz E, Mou Z. 2008. The Arabidopsis MAP kinase kinase 7: A crosstalk point between auxin signaling and defense responses? Plant Signaling \& Behavior 3: 272-274.

Zhang ZM, Ma KW, Yuan S, Luo Y, Jiang S, Hawara E, Pan S, Ma W, Song J. 2016. Structure of a pathogen effector reveals the enzymatic mechanism of a novel acetyltransferase family. Nature Structural \& Molecular Biology 23: 847852.

Zhang Z, Wu Y, Gao M, Zhang J, Kong Q, Liu Y, Ba H, Zhou J, Zhang Y. 2012. Disruption of PAMP-induced MAP kinase cascade by a Pseudomonas syringae effector activates plant immunity mediated by the NB-LRR protein SUMM2. Cell Host and Microbe 11: 253-263.

Zhao J. 2015. Phospholipase D and phosphatidic acid in plant defence response: from protein-protein and lipid-protein interactions to hormone signalling. Journal of Experimental Botany 66: 1721-1736.

Zhou H, Lin J, Johnson A, Morgan RL, Zhong W, Ma W. 2011. Pseudomonas syringae type III effector HopZ1 targets a host enzyme to suppress isoflavone biosynthesis and promote infection in soybean. Cell Host \& Microbe 9: 177186.

Zhou H, Monack DM, Kayagaki N, Wertz I, Yin J, Wolf B, Dixit VM. 2005. Yersinia virulence factor YopJ acts as a deubiquitinase to inhibit NF-kappa B activation. Journal of Experimental Medicine 202: 1327-1332.

Zhou J, Wu S, Chen X, Liu C, Sheen J, Shan L, He P. 2014. The Pseudomonas syringae effector HopF2 suppresses Arabidopsis immunity by targeting BAK1. The Plant Journal 77: 235-245.

Zipfel C, Robatzek S, Navarro L, Oakeley EJ, Jones JD, Felix G, Boller T. 2004. Bacterial disease resistance in Arabidopsis through flagellin perception. Nature 428: 764-767. 


\section{Supporting Information}

Additional Supporting Information may be found online in the Supporting Information section at the end of the article.

Fig. S1 Confocal microscopy imaging showing HopZ1a, MKK7, MKK4, MKK5 and CBL subcellular localisation in planta.

Fig. S2 Analysis of $M K K 7, M K K 9, M K K 4$ and $M K K 5$ expression by RT- $q \mathrm{PCR}$ in Col-0 and MKK7 transgenic plants used in this work.

Fig. S3 Phenotyping images and conductivity assays for DEX:: MKK7 transgenic Arabidopsis plants.

Fig. 44 Dynamics of flg22-induced ROS burst.

Fig. S5 Basal defence phenotyping of $m k k 7$ mutant vs asMKK7 plants.
Fig. S6 HopZ1a acetylation of MKK7 in lysine 167 in vitro and in planta.

Fig. S7 Arabidopsis MKK7 amino acid sequence and structure comparison with relevant kinases.

Methods S1 RNA extraction and RT- $q$ PCR.

Methods S2 Plant material ( $m k k 7$ mutant plants).

Please note: Wiley Blackwell are not responsible for the content or functionality of any Supporting Information supplied by the authors. Any queries (other than missing material) should be directed to the New Phytologist Central Office.

\section{About New Phytologist}

- New Phytologist is an electronic (online-only) journal owned by the New Phytologist Foundation, a not-for-profit organization dedicated to the promotion of plant science, facilitating projects from symposia to free access for our Tansley reviews and Tansley insights.

- Regular papers, Letters, Viewpoints, Research reviews, Rapid reports and both Modelling/Theory and Methods papers are encouraged. We are committed to rapid processing, from online submission through to publication 'as ready' via Early View our average time to decision is $<26$ days. There are no page or colour charges and a PDF version will be provided for each article.

- The journal is available online at Wiley Online Library. Visit www.newphytologist.com to search the articles and register for table of contents email alerts.

- If you have any questions, do get in touch with Central Office (np-centraloffice@lancaster.ac.uk) or, if it is more convenient, our USA Office (np-usaoffice@lancaster.ac.uk)

- For submission instructions, subscription and all the latest information visit www.newphytologist.com 